\title{
Walker circulation controls ENSO atmospheric feedbacks in uncoupled and coupled climate model simulations
}

\author{
Tobias Bayr $^{1}$ (D) $\cdot$ Dietmar Dommenget $^{2} \cdot$ Mojib Latif $^{1,3}$
}

Received: 18 June 2019 / Accepted: 24 January 2020 / Published online: 5 February 2020

(c) The Author(s) 2020

\begin{abstract}
Many climate models strongly underestimate the two most important atmospheric feedbacks operating in El Niño/Southern Oscillation (ENSO), the positive (amplifying) zonal surface wind feedback and negative (damping) surface-heat flux feedback (hereafter ENSO atmospheric feedbacks, EAF). This hampers a realistic representation of ENSO dynamics in these models. Here we show that the atmospheric components of climate models participating in the 5th phase of the Coupled Model Intercomparison Project (CMIP5) when forced by observed sea surface temperatures (SST), already underestimate EAF on average by $23 \%$, but less than their coupled counterparts (on average by $54 \%$ ). There is a pronounced tendency of atmosphere models to simulate stronger EAF, when they exhibit a stronger mean deep convection and enhanced cloud cover over the western equatorial Pacific (WEP), indicative of a stronger rising branch of the Pacific Walker Circulation (PWC). Further, differences in the mean deep convection over the WEP between the coupled and uncoupled models explain a large part of the differences in EAF, with the deep convection in the coupled models strongly depending on the equatorial Pacific SST bias. Experiments with a single atmosphere model support the relation between the equatorial Pacific atmospheric mean state, the SST bias and the EAF. An implemented cold SST bias in the observed SST forcing weakens deep convection and reduces cloud cover in the rising branch of the PWC, causing weaker EAF. A warm SST bias has the opposite effect. Our results elucidate how biases in the mean state of the PWC and equatorial SST hamper a realistic simulation of the EAF.
\end{abstract}

\section{Introduction}

The Pacific Walker Circulation (PWC) is an equatorial zonal circulation cell that arises from the zonal sea surface temperature (SST) difference between the cold tongue region in the eastern equatorial Pacific (EEP) and the warm pool region in the western equatorial Pacific (WEP) (Philander 1990). The rising branch of the PWC is situated over the warm pool region where due to the warm SSTs the vertical structure of the atmosphere is quite unstable (Gadgil et al. 1984; Graham and Barnett 1987; Tompkins 2001). Due to the cold SSTs in the EEP, the vertical structure of the atmosphere is quite stable and therefore the radiative cooling driven descending

Tobias Bayr

tbayr@geomar.de

1 GEOMAR Helmholtz Centre for Ocean Research Kiel, Düsternbrooker Weg 20, 24105 Kiel, Germany

2 School of Mathematical Sciences, Monash University, Clayton, VIC, Australia

3 Cluster of Excellence "The Future Ocean”, University of Kiel, 24105 Kiel, Germany branch of the PWC is situated over the cold tongue region. This circulation cell is closed by upper-level westerlies and low-level easterlies. The easterly winds at the surface lower the thermocline in the WEP and lift the thermocline in EEP, and therefore maintain the temperature difference by driving a divergent equatorial ocean circulation in the EEP (Philander 1990; Graham and Brown 2014). The PWC determines the equatorial atmospheric mean state over the Pacific by influencing the mean humidity, cloud cover, precipitation, shortwave and longwave radiation and latent heat flux (Yu and Zwiers 2010; Yu et al. 2012; Bayr et al. 2014, 2018) and is coupled to the mean state of the ocean (Dijkstra and Neelin 1995).

The growth of anomalies related to the El Niño/Southern Oscillation (ENSO) strongly depends on interplay of the positive (amplifying) zonal wind-SST feedback and the negative (damping) heat flux-SST feedback, which arise from air-sea interactions between the PWC and the tilted thermocline (Jin 1997; Neelin et al. 1998; Wang and Picaut 2004; Timmermann et al. 2018). During El Niño, a weakening of the trade winds over the western and central equatorial Pacific reduces the thermocline tilt across the equatorial 
Pacific and causes a warming of the SST primarily in the central and eastern Pacific where the thermocline is shallow. This in turn further weakens the trade winds. During La Niña, stronger trade winds drive cooling of the SST over the central equatorial Pacific due to enhanced upwelling of cool subsurface waters. The wind-SST feedback is caused by changes in the zonal SST gradient and a zonal shift in atmospheric deep convection which is linked to the rising branch of the PWC (Philander 1990; Bayr et al. 2014, 2018). The most important negative atmospheric feedback operating in ENSO is the surface net heat flux feedback (Guilyardi et al. 2009b). Two components dominate the negative feedback: First, the cloud-SST (or shortwave-SST) feedback that is most prominent over the WEP where the largest changes in deep convection occur. This in turn influences the incoming shortwave radiation at the surface due to changes in cloudiness. Second, the evaporation-SST (or latent heat flux-SST) feedback which is most prominent over the EEP due to the large SST changes in this region, as it strongly depends on the SST (Lloyd et al. 2009, 2011, 2012; Dommenget et al. 2014; Dommenget and Yu 2016; Bayr et al. 2018).

The positive zonal wind feedback and the negative surface net heat flux feedback operating in ENSO (hereafter collectively termed ENSO atmospheric feedbacks, EAF) are strongly underestimated in most Coupled General Circulation Models (CGCM) participating in the 5th phase of the Coupled Model Intercomparison Project (CMIP5) (Taylor et al. 2012). The feedback strengths range from close to observations to only one-third of the observed strength (Bayr et al. 2018). Further, an error compensation is observed between the underestimated zonal wind and surface net heat flux feedbacks (Guilyardi et al. 2009b; Lloyd et al. 2009; Bellenger et al. 2014; Kim et al. 2014; Vijayeta and Dommenget 2018; Bayr et al. 2018, 2019). Biases in the AGCM physics and a biased mean state were suggested as two important factors for the too weak EAF in climate models, with the latter influenced by the former (Lloyd et al. 2009, 2011, 2012; Dommenget et al. 2014; Bayr et al. 2018).

The wind feedback strength is quite diverse in simulations of Atmospheric General Circulation Models (AGCM) in the CMIP3 data base, that are forced by the same observed SSTs and boundary conditions: one-third of the models has stronger, one-third weaker and one-third similar wind feedbacks in comparison with observations, but nearly all AGCMs underestimate the heat flux feedback (see Fig. 1 in Lloyd et al. 2011). Further, most CGCMs tend to have weaker EAF in the coupled simulations than in AMIP (Lloyd et al. 2011). These authors analyzed how model physics influences the EAF strength, and cloud and convection parametrizations have been identified as a major factor of uncertainty (Lloyd et al. 2011). Especially the strength of the heat flux feedback is very sensitive to the choice of the convection scheme (Guilyardi et al. 2009a). In coupled models Bayr et al. (2018) separated the influence of biases in the atmospheric model physics on the EAF from that of the biased mean state in the Kiel Climate Model (KCM). In this CGCM, the biased mean state accounts for the largest part of the biases in the EAF strength while the biases in the AGCM's physics play a smaller role (Bayr et al. 2018). Especially an equatorial cold SST bias, which is a common problem in many climate models, hampers both atmospheric feedbacks, as it shifts the PWC into a La Niña-like mean state with a too westward position of the rising branch of the PWC (Bayr et al. 2018, 2019). Consistent with this result, the analysis of a set of CMIP5 models reveals that models with a large equatorial cold SST bias tend to have weaker EAF (see Fig. 11d-f in Bayr et al. 2018). Further it also explains the error compensation between the underestimated wind-SST and heat flux-SST feedback seen in many climate models, as both feedbacks strongly depend on mean state of the PWC (Bayr et al. 2018, 2019).

In summary we know from literature, that on the one hand the uncertainties in the model physics are an important factor for the difference in simulated EAF strength in the AGCMs and that on the other hand the coupled mean state has a large influence on the EAF strength in coupled models. It is important to note that in general the coupled mean state itself and its biases depend strongly on the model physics, as described e.g. in Dijkstra and Neelin (1995). But it is still an open question if the atmospheric mean state is also important for the EAF strength in atmosphere only simulations and what is causing the difference in EAF strength between the corresponding AGCM and CGCM simulations. For this purpose we focus here on the atmospheric components of the CGCMs and investigate how the models of the 5th phase of the Atmospheric Model Intercomparison Project (AMIP5) perform, when forced by observed SSTs, in comparison to the CGCMs. Further, we investigate the atmospheric mean-state influence on the EAF strength in the AGCMs and the difference in EAF strength between the AGCMs and CGCMs. Finally, we illustrate in experiments with a single AGCM the influence of the atmospheric mean state on the EAF strength by implementing different equatorial SST biases in the observed SST forcing. The paper is organized as follows: In Sect. 2 we introduce the model data and methods used in this study. We analyze the EAF strength in the AMIP5 and CMIP5 ensembles in Sect. 3 and the relation of the EAF strength to the atmospheric mean state in Sect. 4. In Sect. 5, we report the results from the AGCM experiments to support the mean state dependence of the EAF. We summarize and discuss the major results in Sect. 6.

\section{Data and methods}

Observed SSTs are taken from NOAA-OISST for the period 1982-2016 (Banzon et al. 2016). Near surface (10 m) zonal wind (U10), vertical wind at $500 \mathrm{hPa}$ and heat fluxes for 
the period 1982-2016 are taken from ERA-Interim reanalysis (Simmons et al. 2007). Observed precipitation for the period 1982-2016 is taken from CMAP data set (Xie and Arkin 1997) and observed total cloud cover for the period 1984-2009 from ISCCP (Rossow and Schiffer 1999).

We analyze a set of historical simulations (1900-1999) and AMIP experiments (1979-2008) of a multi-model ensemble from the CMIP5 database (Taylor et al. 2012). The AMIP experiments allow insight into the biases inherent to the AGCMs, as the models are forced by observed SSTs. It is important to note, that we have a two-way coupling between the SST and the atmosphere in the CGCMs, but only a one-way coupling in the AGCM. But for the purpose of this study AGCM experiments are suitable, as they allow to investigate the relation between SST and the atmospheric circulation (He et al. 2018). The data is interpolated onto a regular $2.5^{\circ} \times 2.5^{\circ}$ grid and we use all models with the required data available (see Fig. 1 for a list of the models).

Additionally we use coupled and uncoupled experiments of the Kiel Climate Model (KCM) (Park et al. 2009). The KCM consists of the ECHAM5 AGCM (Roeckner 2003) with a resolution of $\mathrm{T} 42\left(\sim 2.8^{\circ} \times 2.8^{\circ}\right)$ in the horizontal and 31 vertical levels and the NEMO ocean general circulation model (Madec et al. 1998; Madec 2008) with a $\sim 2^{\circ}$ horizontal resolution with a latitudinal refinement up to $\sim 0.5^{\circ}$ in the equatorial region and 31 vertical levels. We additionally performed a series of uncoupled experiments with the ECHAM5 AGCM. In a control experiment (called AMIPtype), we prescribed observed daily SSTs for the period 1982-2016 from NOAA-OISST (Banzon et al. 2016). To investigate the relation between the atmospheric mean state and the EAF, we perform sensitivity experiments in which we force the atmosphere into different mean states by adding the annual-mean SST biases from 6 CMIP5 models to the observed SST data set at each time step. These 6 CMIP5 models are the ones with the weakest EAF (less than 0.35 of the observed strength in both zonal wind and net heat flux feedback) as shown in Fig. 1a (green numbers). For these AGCM-sensitivity experiments, we only choose the cold SST bias in the region $130^{\circ} \mathrm{E}-90^{\circ} \mathrm{W}, 8^{\circ} \mathrm{S}-8^{\circ} \mathrm{N}$ and neglect the SST biases elsewhere. We vary the magnitude of the implemented SST bias from a large cold SST bias of 2.25 times the CMIP5 SST bias to a small warm SST bias of 0.75 times the CMIP5 SST bias with an increment of 0.25 . The implemented cold SST bias is strongest in the western Pacific (2.6 times larger in the Niño4 region than in the Niño3 region) and the individual sensitivity experiments are labeled according to their relative SST bias in the Niño4 region.

The Niño3 region is defined as $90^{\circ} \mathrm{W}-150^{\circ} \mathrm{W}$ and $5^{\circ} \mathrm{S}-5^{\circ} \mathrm{N}$, the Niño3.4 region as $120^{\circ} \mathrm{W}-170^{\circ} \mathrm{W}$ and $5^{\circ} \mathrm{S}-5^{\circ} \mathrm{N}$, and the Niño4 region as $160^{\circ} \mathrm{E}-150^{\circ} \mathrm{W}$ and $5^{\circ} \mathrm{S}-5^{\circ} \mathrm{N}$. Monthly-mean values are used in the analyses below. Anomalies are with respect to the climatological seasonal cycle and the linear trend is subtracted for each month separately.

To define ENSO events we use the criterion of Trenberth (1997): an El Niño (La Niña) event occurs if the 5-month running mean SST anomaly in the Niño3.4 region is above 0.5 (below -0.5 ) times the standard deviations for at least six consecutive months. To illustrate the time evolution of ENSO events we show composite-Hoevmoeller diagrams along the equatorial Pacific $\left(5^{\circ} \mathrm{S}-5^{\circ} \mathrm{N}\right)$ (Fig. 2). For better comparison, all variables are normalized with the mean Niño3.4 SST anomalies 3 months before and after the maximum of all events. The Hoevmoeller diagrams are centered in time on the month of the maximum of the compositeENSO event (lag 0). The maximum of an El Niño ( $\mathrm{La}$ Niña) event is defined for each event individually using the 5-month running mean Niño3.4 SST anomalies during this event.

We define the zonal wind feedback as the U10 response to the SST anomalies in the composite-Hoevmoeller diagram averaged over the WEP (Niño4 region) and \pm 3 months around the peak of the ENSO event (black box in Fig. 2b). We use here U10 instead of wind stress, as wind stress was not available for all models and U10 is more comparable between the models due to differences in wind stress calculation between the models (see Bayr et al. 2019 for more details). But we have to note that it is the wind stress that drives the ocean circulation. The surface net heat flux feedback is defined as the $\mathrm{Q}_{\text {net }}$ response to the SST anomalies averaged over the eastern equatorial (Niño3 region) and western equatorial Pacific (Niño4 region) (black box in Fig. 2c). The vertical wind response during ENSO events is defined as the average over the Niño4 region (black box in Fig. 2d) and the cloud cover response as the average over the Niño3 and Niño4 region (black box in Fig. 2e). The feedback strengths are normalized with the SST anomalies averaged over the central equatorial Pacific (Niño3.4 region), so that we yield changes per Kelvin SST change, similar to a regression. Further, we use same regions to define the feedbacks in each model, even the equatorial SST bias shifts the maximum of the atmospheric response to different longitudes in the models. Fixed regions have the advantage to better reveal the effect of the equatorial SST bias.

To calculate the SST bias, we first compute the mean relative SST with respect to the area mean of the tropical IndoPacific $\left(40^{\circ} \mathrm{E}-70^{\circ} \mathrm{W}, 15^{\circ} \mathrm{S}-15^{\circ} \mathrm{N}\right)$, since climate models tend to have different global mean temperatures which shifts the threshold of convection (Bayr and Dommenget 2013). Further, due to moist-adiabatic adjustment of the tropical atmosphere relative SST is more appropriate to describe the relation between SST and convection than absolute SSTs (Johnson and Xie 2010; He et al. 2018). The SST bias is then the relative SST of the climate model minus the observed relative SST. We 


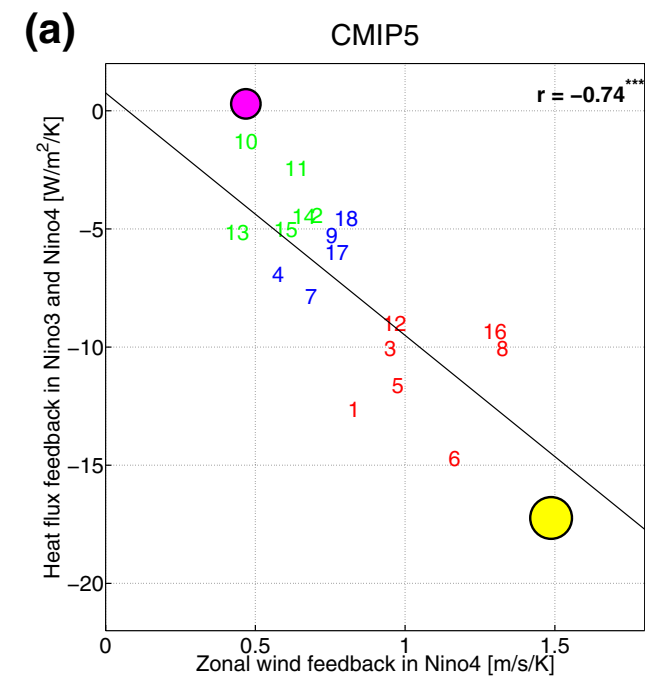

(c) CMIP5 vs. AMIP5

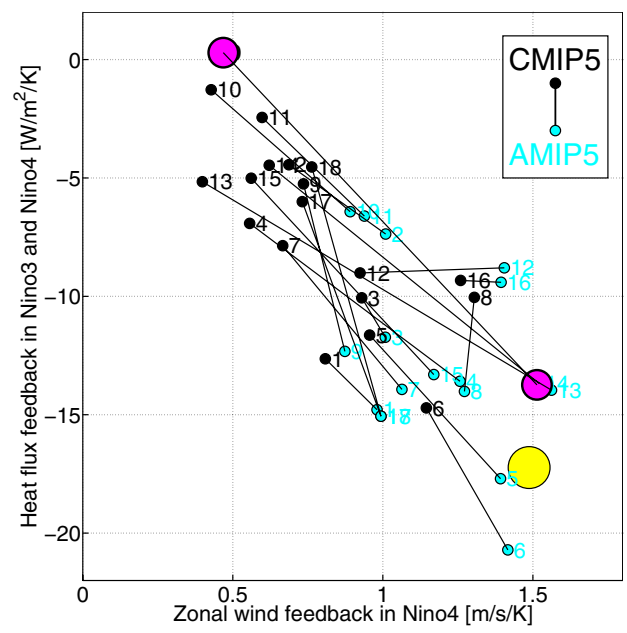

Fig. 1 Zonal wind feedback vs. net heat flux feedback in ENSO in a ERA-Interim, KCM and the individual CMIP5 models; b same as a but here for the corresponding AMIP5 experiments, atmosphere only experiment of KCM and ERA-Interim; The colors of the numbers in $\mathbf{a}$ and $\mathbf{b}$ indicate the members of the three sub-ensembles with STRONG (red), MEDIUM (blue) and WEAK (green) atmospheric feedbacks in CMIP5 and AMIP5 ensembles, respectively, as used in the following; $\mathbf{c}$ same as a and $\mathbf{b}$, but here the CMIP5 experiments are shown in black and the corresponding AMIP5 experiments are shown

use the relative SST bias over the Niño4 region as a reference, as this region has the strongest influence on the strength of EAF in the coupled models (Bayr et al. 2018).

\section{Atmospheric feedbacks in CMIP5 and AMIP5}

The strength of the zonal wind-SST and net heat flux-SST feedback is shown for ERA-Interim, the KCM, and a set of CMIP5 models and the corresponding AMIP5 experiments (b) AMIP5

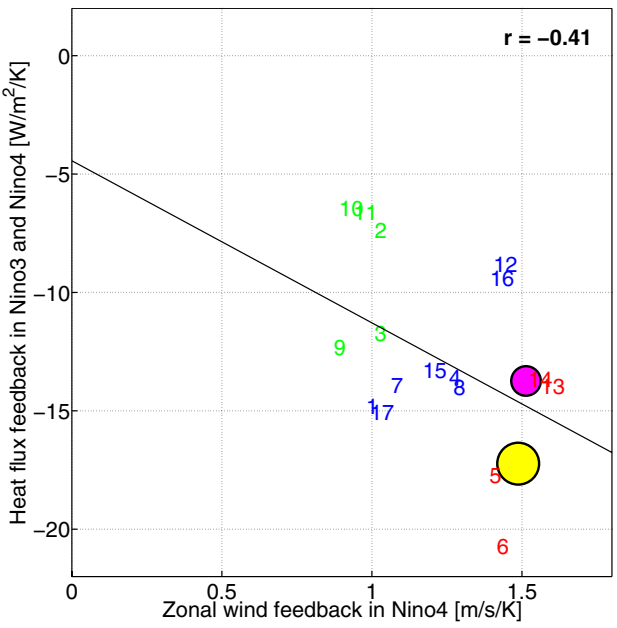

ERA-Interim
0 Kiel Climate Model
1: ACCESS1-0
2: ACCESS1-3
3: BNU-ESM
4: CanESM2
5: CMCC-CM
6: CNRM-CM5
7: GFDL-CM3
8: GISS-E2-R
9: INM-CM4
10: IPSL-CM5A-LR
11: IPSL-CM5A-MR
12: MIROC5
13: MPI-ESM-LR
14: MPI-ESM-MR
15: MRI-CGCM3
16: NorESM1-ME
17: HadGEM2-CC
18: HadGEM2-ES

in cyan and the corresponding experiments are linked by a black line. Values shown here are the averages over the boxes as shown in Fig. 2b and c for ERA Interim, i.e. for wind feedback over the Niño4 region, and for heat flux feedback over the Niño3 and Niño4 region in the space domain, and \pm 3 months before and after the maximum of the ENSO events in time domain; The correlation between the individual experiments is given in $\mathbf{a}$ and $\mathbf{b}$ in the upper right corner and one, two or three stars indicate a significant correlation on a $90 \%$, $95 \%$ or $99 \%$ confidence level, respectively

in Fig. 1a, b). There is a large spread in EAF in the CMIP5 models: some models have EAF close to reanalysis, others have strongly underestimated EAF with both feedbacks less than a third of the observed feedback strength. There is a strong relation between the zonal wind-SST and net heat flux-SST feedback in the CMIP5 models, which reveals error compensation in many climate models (Bayr et al. 2018, 2019). When driving the atmosphere models with observed SSTs the EAF are much closer to the observed strength, but also in AMIP5 most models underestimate both EAF (Fig. 1b). The sign of the correlation between the two 
ENSO Composites in Obs and AMIP5
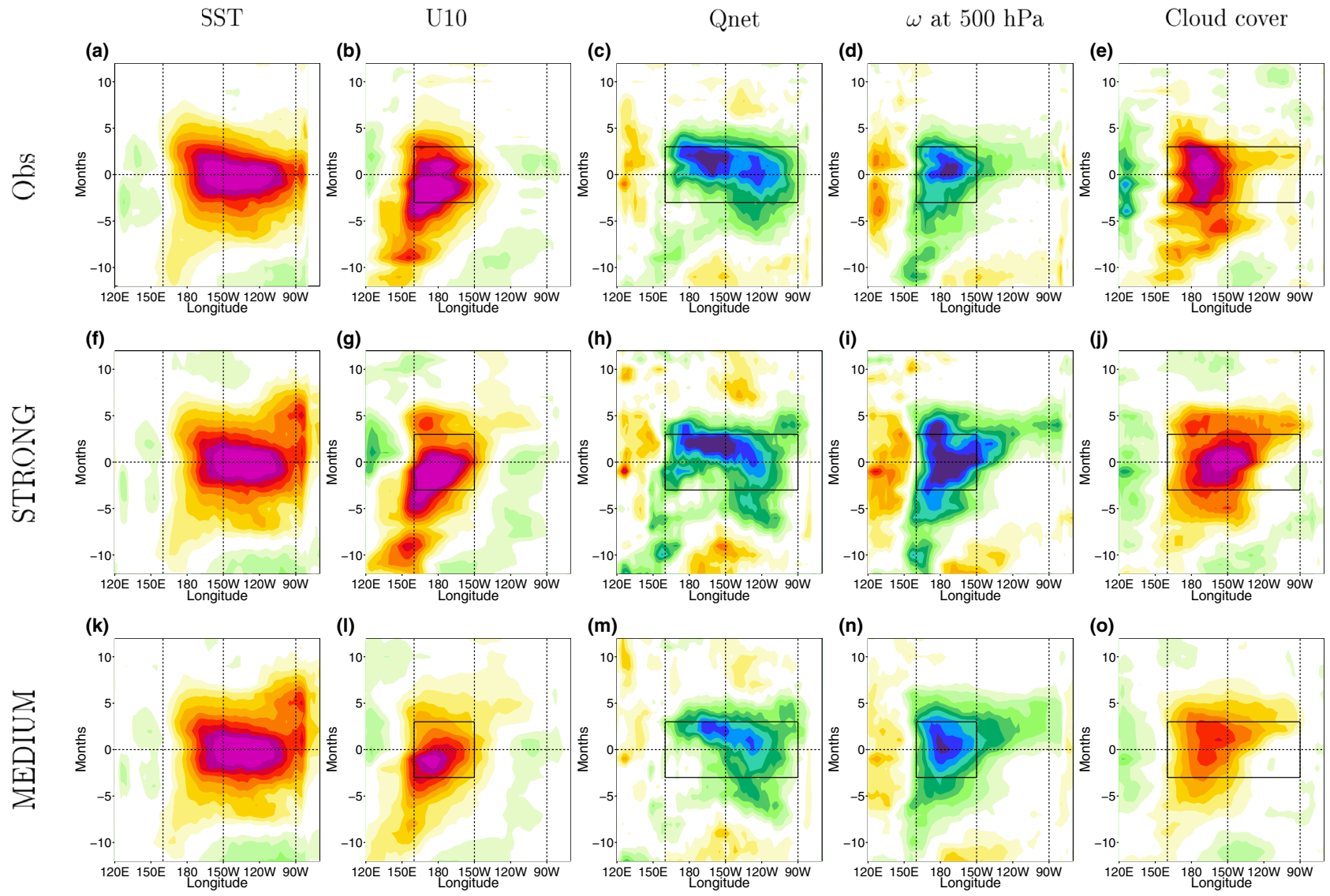

(p)

(q)
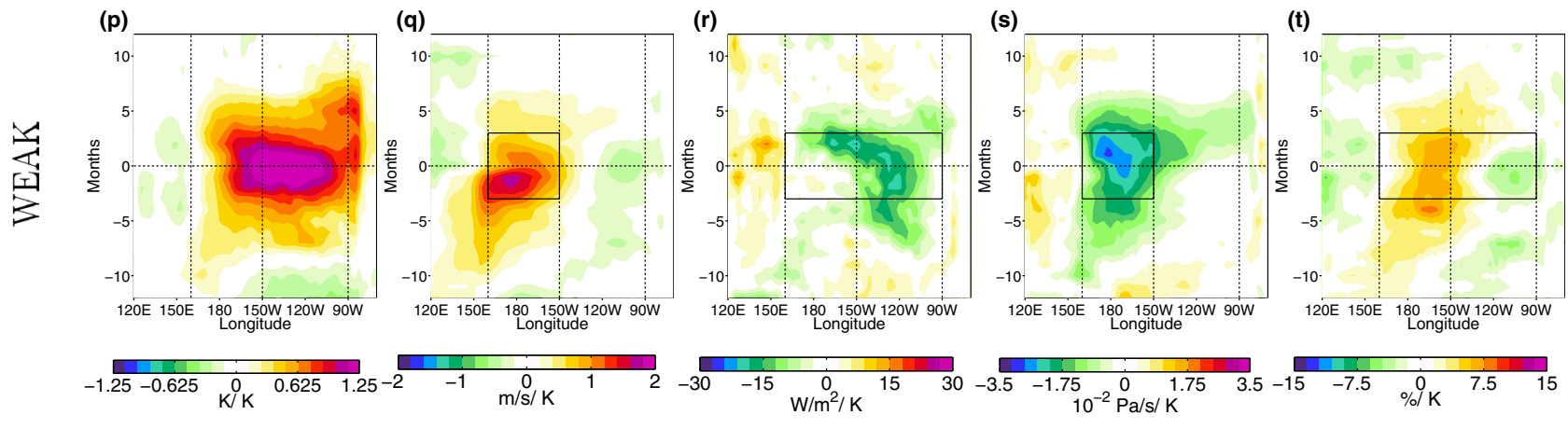

Fig. 2 Composite Hoevmoeller diagrams of El Niño and La Niña events of the equatorial Pacific (averaged between $5^{\circ} \mathrm{S}$ and $5^{\circ} \mathrm{N}$ ), with five month running mean Niño3.4 index $>0.5 \mathrm{I}<-0.5$ standard deviations as selection criterion according to Trenberth (1997) for observations/reanalysis data in a sea surface temperature (SST), in b zonal wind in $10 \mathrm{~m}$ height (U10), in c net heat flux (Qnet) in d vertical wind in $500 \mathrm{hPa}$ (omega, negative upward), in e total cloud cover; $\mathbf{f}-\mathbf{j}$ same as $\mathbf{a}-\mathbf{e}$, but here for the AMIP5 sub-ensemble with

feedback strengths is the same in AMIP5 as in CMIP5, but insignificant in AMIP5 due to a smaller signal to noise ratio.

Figure 1c highlights that EAF are stronger in 15 out of 18 (83\%) corresponding AMIP experiments than in their coupled counterparts and most models show a similar direction of reduction of both feedbacks from AMIP5 to CMIP5 but in
STRONG atmospheric feedbacks; k-o same as a-e, but here for the AMIP5 sub-ensemble with MEDIUM atmospheric feedbacks; p-t same as a-e, but here for the AMIP5 sub-ensemble with WEAK atmospheric feedbacks; All variables are normalized with mean Niño3.4 SST 3 months before and after the maximum of the events and are centered in time on the month of the maximum of the ENSO events (lag 0). The dashed lines mark the Niño3 and Niño4 regions and the maximum of the ENSO events in time

different amounts (black lines). Only two models (MIROC5 and NorESM1-ME) show a reduction in zonal wind feedback while the net heat flux feedback stays about the same, and one model (GISS-E2-R) shows a reduction in the net heat flux feedback while the zonal wind feedback slightly increases. The simultaneous reduction of both feedbacks 
from AMIP5 to CMIP5 in most models suggests that the reduction is linked to changes in the mean state as suggested in Bayr et al. (2018, 2019).

For further analysis we define sub-ensembles with STRONG, MEDIUM and WEAK atmospheric feedbacks, according to their total atmospheric feedback strength defined as the average of the two feedbacks after normalizing each by the ERA-Interim value. Models in STRONG have a total atmospheric feedback strength larger than 0.5 and 0.85 for CMIP5 and AMIP5, respectively, models in WEAK smaller than 0.35 and 0.7 , and models in MEDIUM between STRONG and WEAK. The three sub-ensembles are indicated by red (STRONG), blue (MEDIUM) and green (WEAK) color in Fig. 1a, b) and in the following.

The atmospheric response to Niño3.4 SST anomalies 12 months before and after the peak of the ENSO events is shown for reanalysis/observations and the three AMIP5 subensembles in Fig. 2 by composite-Hoevmoeller diagrams. In reanalysis and observations, the strongest response in $\mathrm{U} 10$, vertical wind at $500 \mathrm{hPa}$ and cloud cover is over the Niño4 region (Fig. 2b, d, f) and the strongest response in the net heat flux over the combined Niño3/Niño4 region (Fig. 2c). The AMIP5 sub-ensemble with STRONG atmospheric feedbacks has a quite realistic zonal wind and net heat flux feedback in pattern and amplitude, but too strong vertical wind and cloud cover responses (Figs. 2f-j, 3). The MEDIUM sub-ensemble has a realistic vertical wind response, but the zonal wind, net heat flux and cloud cover responses are underestimated (Figs. 2k-o, 3). The WEAK sub-ensemble underestimates the response in all four variables (Figs. 2p-t, 3). Figure 3 summarizes the differences in amplitude between observations and the three AMIP5 subensembles. These results suggest a link between the strength of the convective response over the WEP and the $10 \mathrm{~m}$-zonal wind and net heat flux response in the AMIP models.

This can be highlighted in the individual AMIP5 models, as they show a quite strong correlation of -0.72 between the $10 \mathrm{~m}$-zonal wind feedback and the vertical wind response at $500 \mathrm{hPa}$, both in Niño4 (Fig. 4a), and of -0.80 between the net heat flux feedback and the cloud cover response, both in Niño3/Niño4 (Fig. 4d). Most AMIP models simulate a realistic or stronger than observed vertical wind response but a too weak zonal wind feedback, pointing towards a general problem in these models (Fig. 4a). We observe a similar relation in the CMIP5 models, but generally with weaker atmospheric responses per K warming of Niño3.4 SST (Fig. 4b, e). This suggests that model physics alone cannot explain the EAF strength, as the corresponding AMIP5 and CMIP5 models have the same model physics. Further, the reduction of the zonal wind feedback from AMIP5 to CMIP5 is linked to the weaker vertical wind response (Fig. 4c) and the concurrent reduction of the net heat flux feedback to the weaker cloud cover response (Fig. 4f).

ECHAM5, the AGCM of the KCM, has the strongest vertical wind and cloud cover response of all AGCMs and similar zonal wind and net heat flux feedbacks as the AMIP5 models in the STRONG sub-ensemble (Fig. 4a, d). But in coupled mode a very weak EAF and atmospheric response (Fig. 4b, e) is observed in KCM, giving rise to the largest differences between an AGCM and CGCM (Fig. 4c, f). We note that ECHAM5 exhibits a quite similar behavior as ECHAM6, the AGCM in the MPI-ESM (numbers 13 and 14). We will focus later more in detail on the differences of EAF between the AMIP5 and CMIP5 models. But next we want to have a closer look, how the differences in the EAF of the AMIP5 models can be explained.
Fig. 3 Amplitude of U10 in Niño4, Qnet in Niño3 and Niño4, omega in Niño4 and cloud cover in Niño3 and Niño4, all lag \pm 3 months around the maximum of the ENSO events, as indicated by the black boxes in the composite Hoevmoeller diagrams in Fig. 2. Note that the amplitudes are scaled for better plotting by the factors given on the $\mathrm{x}$ labels

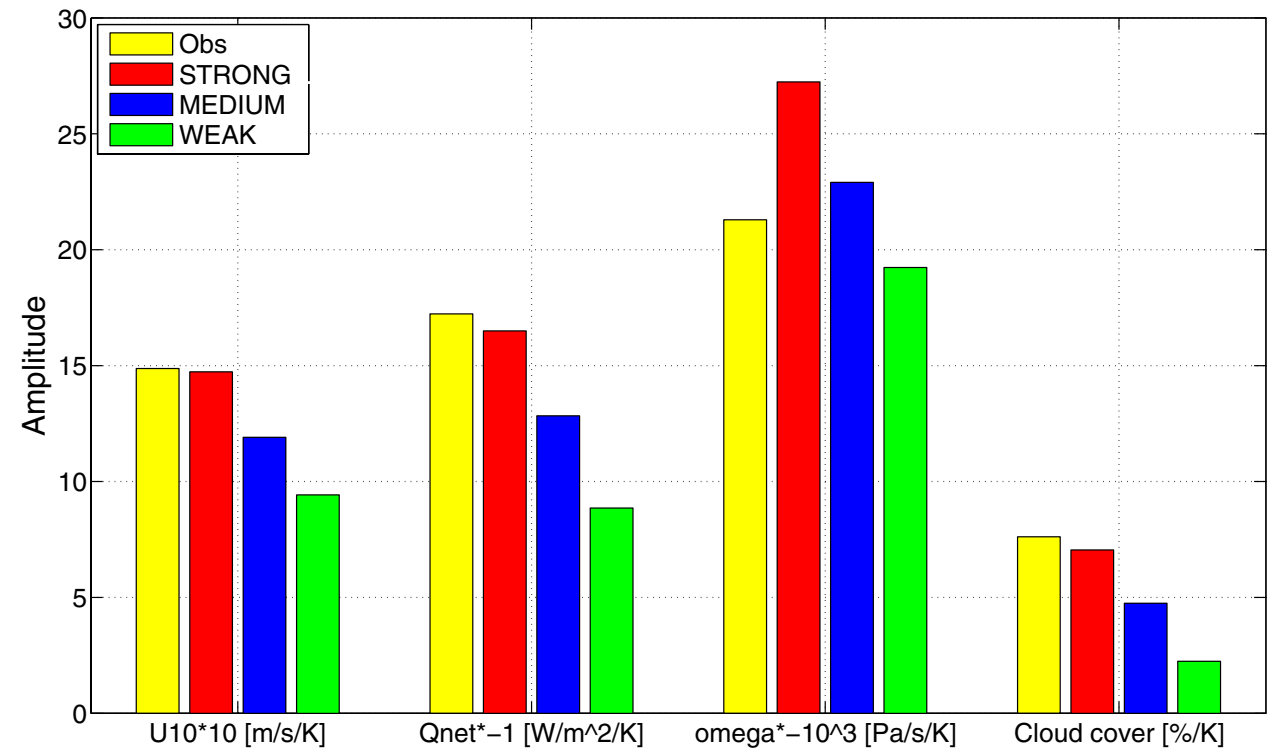




\section{Feedbacks in}
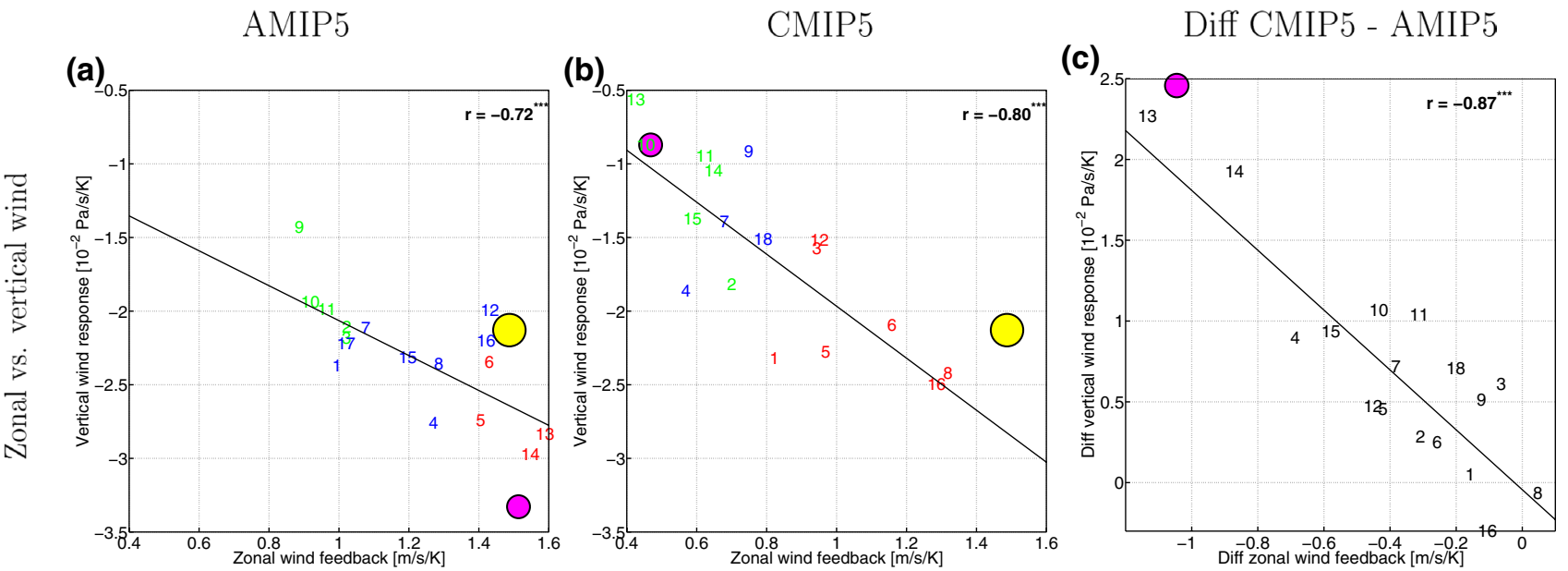

(d)

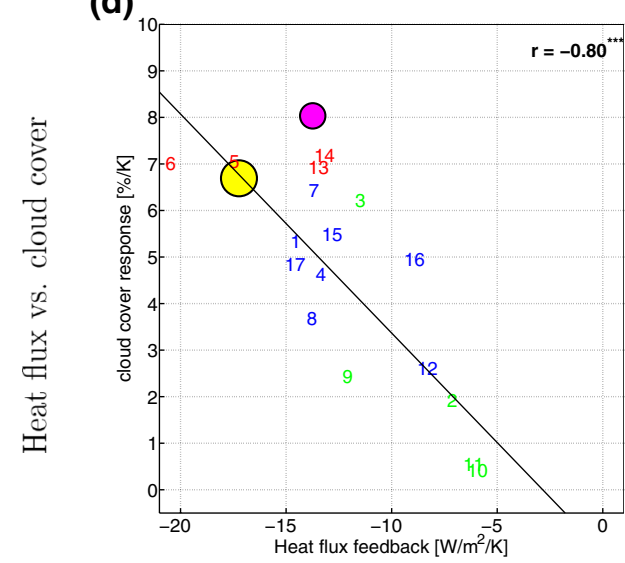

(e)

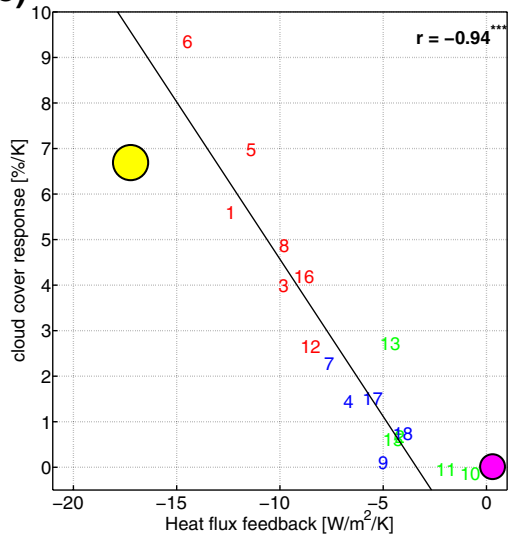

(f)

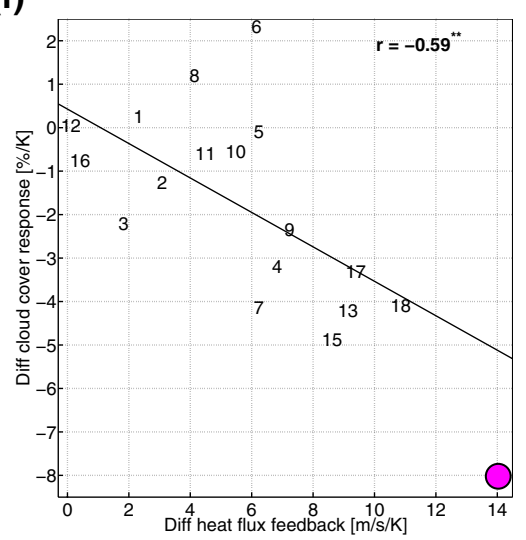

Fig. 4 a Same as Fig. 1b), but here for the vertical wind response at $500 \mathrm{hPa}$ in Niño4 on y-axis (as shown in Fig. 2d) for ERA-Interim); in b same as a, but here for CMIP5 models; $\mathbf{c}$ same as a but here the difference CMIP5-AMIP5; $\mathbf{d}-\mathbf{f}$ same as $\mathbf{a}-\mathbf{c}$ but here for the heat

\section{Mean state and atmospheric feedback strengths in AMIP5 and CMIP5}

As all AMIP5 models employ the same SSTs, the differences in the EAF between them should arise primarily from the differences in model physics. The latter influences the atmospheric dynamics and the atmospheric mean state. Figure 5 shows the mean zonal wind, vertical wind, precipitation and cloud cover along the equator from observations and the three AMIP5 sub-ensembles. The STRONG sub-ensemble has weaker mean easterly surface winds, more ascending motion, and more precipitation in the western Pacific $\left(150^{\circ} \mathrm{E}-180^{\circ}\right)$, and more cloud cover in the western and less cloud cover in the central Pacific $\left(150^{\circ} \mathrm{W}-120^{\circ} \mathrm{W}\right)$ than the WEAK sub-ensemble (Fig. 5). This indicates that models with a stronger mean ascent in the western Pacific and a larger cloud cover difference flux feedback in Niño3 and Niño4 on the x-axis vs. the cloud cover response in Niño3 and Niño4 on the y-axis (as shown in Fig. 2e) for observations)

between the western and eastern Pacific have stronger EAF.

In the individual AMIP5 models, there is a strong correlation of 0.78 between the mean vertical velocity over the western Pacific and the vertical wind response over the Niño4 region (Fig. 6a) and of 0.86 between the west-east difference in mean cloud cover and the cloud cover response in the combined Niño3/Niño4 region (Fig. 6d). The question thus arises of how strongly the EAF strength depends on the atmospheric mean state. As the convective response strongly depends on the atmospheric mean state, we hypothesize that the atmospheric physics primarily are important in determining the atmospheric mean state that in turn determines the EAF strength. This is further supported by the fact that the colored numbers are still quite clustered in Fig. 6a, d), which means that there is no AGCM with weak mean convection and strong EAF or vice versa. 


\section{AMIP5: Equatorial mean state}
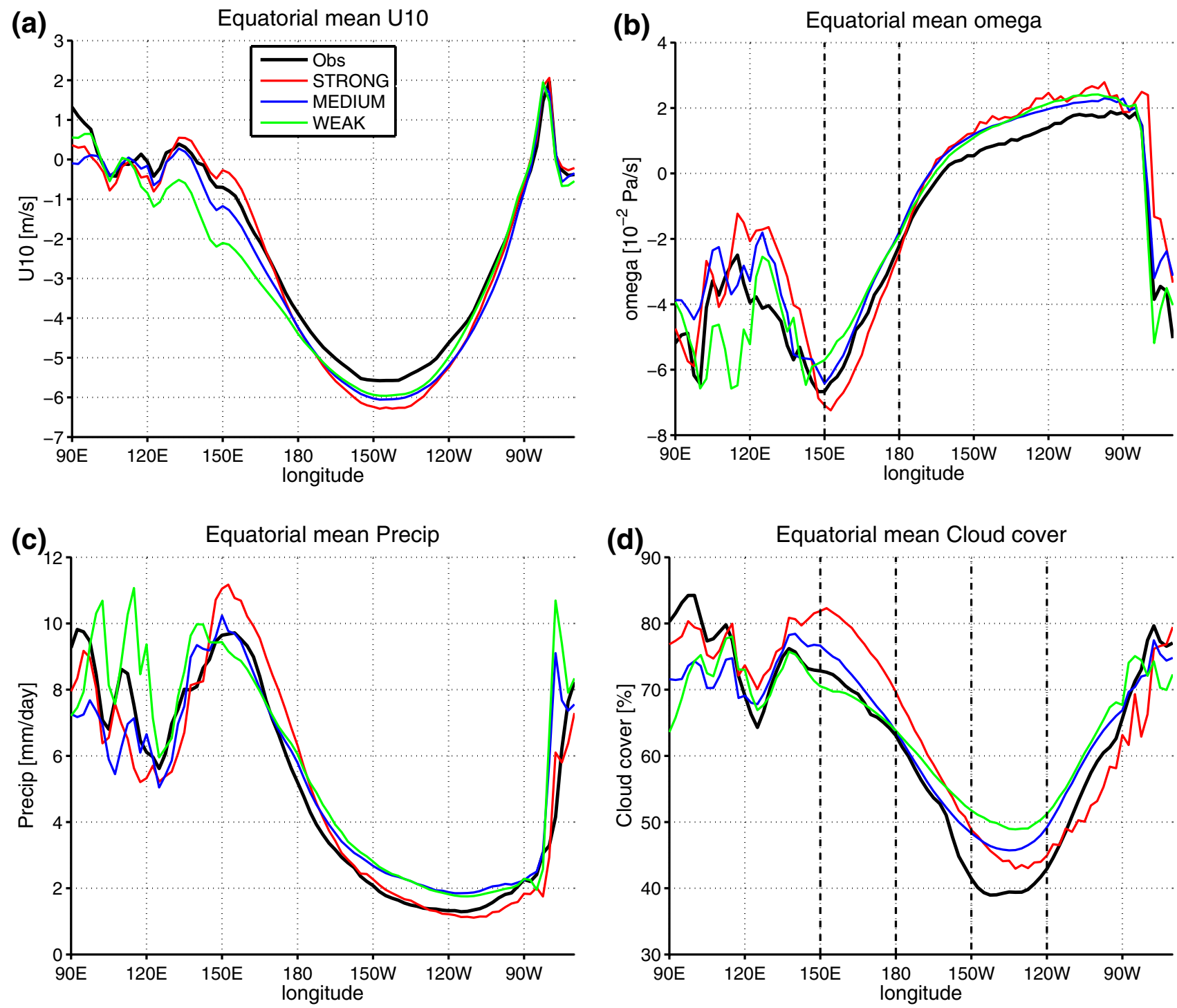

Fig. 5 Equatorial mean state $\left(5^{\circ} \mathrm{S}-5^{\circ} \mathrm{N}\right)$ in reanalysis/observations and in AMIP5 sub-ensembles with STRONG, MEDIUM and WEAK feedbacks; in a for zonal wind at $10 \mathrm{~m}$ height, in $\mathbf{b}$ for vertical wind at $500 \mathrm{hPa}$ (negative upward), in $\mathbf{c}$ for precipitation and in $\mathbf{d}$ for total cloud cover

Additional support for this hypothesis comes from a similar relation between the mean state and the atmospheric response during ENSO events in the CMIP5 models (Fig. 6b, e). The difference in vertical wind and cloud cover response between AMIP5 and CMIP5 can also be explained by the different atmospheric mean state (Fig. 6c, f). Comparing corresponding AMIP5 and CMIP5 experiments indicates that the same model physics with different SSTs (observed vs. simulated SSTs) cause different atmospheric mean states that in turn influence the EAF strength. Moreover, there is a strong negative correlation $(r=-0.83)$ between the equatorial SST bias in the Niño4 region in CMIP5 and the difference between AMIP5 and CMIP5 in mean vertical wind in the western Pacific and mean cloud cover difference (West minus East Pacific) $(\mathrm{r}=0.65)$ (Fig. 7). These analyses suggest a quite substantial influence of the atmospheric mean state in determining the EAF strength in both the AGCMs and CGCMs.

ECHAM5 is the AGCM with the strongest mean deep convection and convective response, as measured by the vertical velocity (Fig. 6a, d), but the KCM is the CGCM with the weakest mean deep convection and convective response (Fig. 6b, e) and largest difference between an AGCM and CGCM (Fig. 6c, f). Again, KCM behaves quite similar to MPI-ESM that employs ECHAM6 as atmospheric component. 


\section{Mean State vs. Feedbacks in}

\section{AMIP5}

(a)

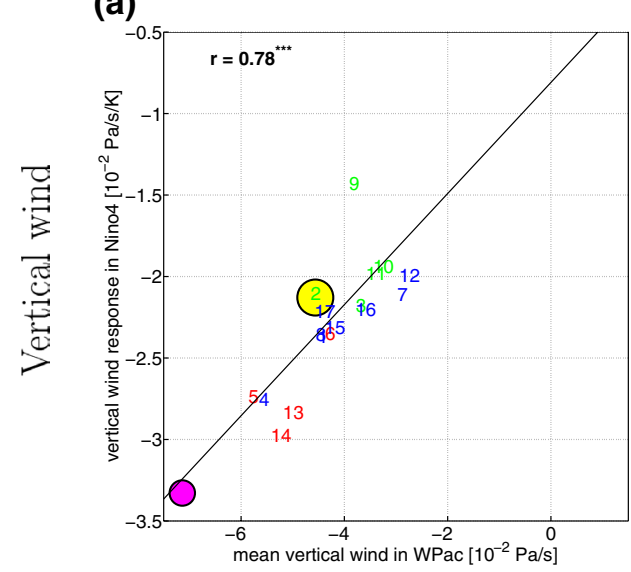

(d)

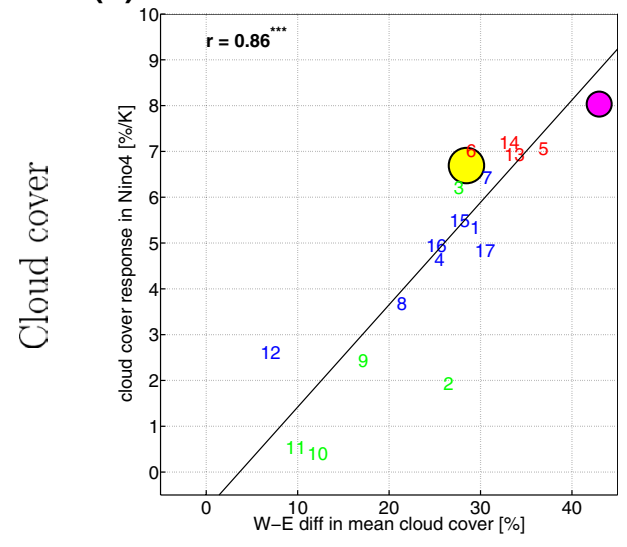

CMIP5

(b)

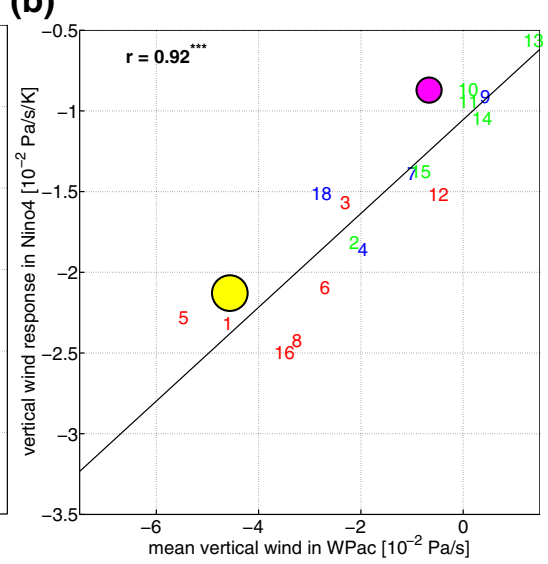

(e)

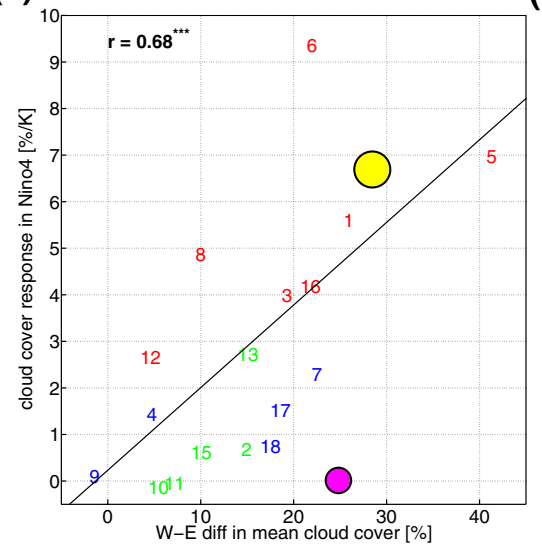

Diff CMIP5 - AMIP5

(c)

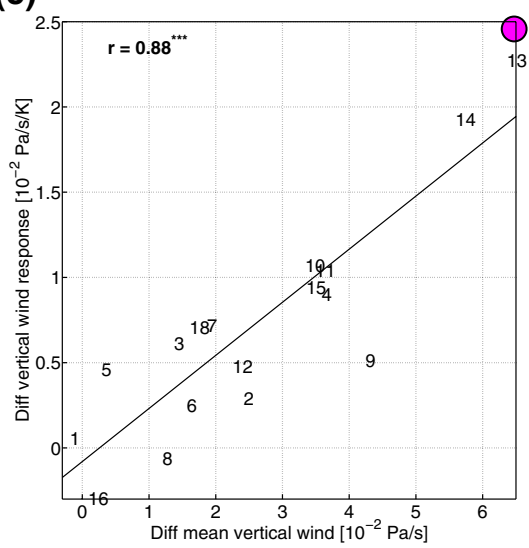

(f)

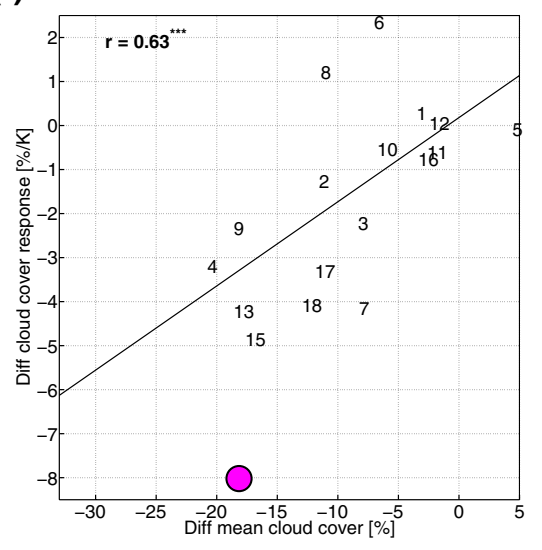

Fig. 6 Mean state vs. feedbacks, in $\mathbf{a}$ in AMIP5 the mean state of vertical wind in $500 \mathrm{hPa}$ in the western Pacific $\left(150^{\circ} \mathrm{E}-180^{\circ}, 5^{\circ} \mathrm{S}-5^{\circ} \mathrm{N}\right.$, as indicated by the dashed vertical lines in Fig. $5 \mathrm{~b}$ ) on the $\mathrm{x}$-axis vs. vertical wind response at $500 \mathrm{hPa}$ in Niño4 during ENSO events on $\mathrm{y}$-axis, in b same as a but here for CMIP5 and in $\mathbf{c}$ same as a but here the difference CMIP5-AMIP5; in $\mathbf{d}-\mathbf{f}$ same as a-c) but here the difference West $\left(150^{\circ} \mathrm{E}-180^{\circ}, 5^{\circ} \mathrm{S}-5^{\circ} \mathrm{N}\right)$ minus East $\left(120^{\circ} \mathrm{W}-150^{\circ} \mathrm{W}\right.$, $5^{\circ} \mathrm{S}-5^{\circ} \mathrm{N}$ ) in mean cloud cover on the $\mathrm{x}$-axis (West and East region are indicated by dashed vertical lines in Fig. 5d) vs. the cloud cover response in Niño3 and Niño4 on the y-axis

\section{Atmospheric feedbacks in different atmospheric mean states}

The above analyses suggest that the atmospheric mean state has an important influence on the EAF strengths and that model physics may play mainly an indirect role by determining the mean state. To support this hypothesis we conduct a series of sensitivity experiments with ECHAM5, in which we generate different atmospheric mean states by changing the SSTs. We superimpose the average equatorial cold SST bias from the WEAK sub-ensemble of the CMIP5 models (Fig. 8) with different amplitudes and signs on the observed SST to force the atmosphere into different mean states. With this approach, we can answer the following questions: First, is it possible to explain the spread in EAF in the AMIP5 ensemble by a single AGCM with different atmospheric mean states? Second, how much of the spread in EAF in the CMIP5 ensemble can be reproduced with an AGCM exhibiting different mean states? Third, can the equatorial cold SST bias explain the reduction of EAF strength from AMIP5 to CMIP5?

By introducing the SST bias in the sensitivity experiments, the warm pool position and equatorial SST gradient structure are altered (Fig. 9a), which in turn has a substantial impact on the atmospheric mean state. A cold (warm) SST bias decreases (increases) mean ascent, precipitation, and cloud cover and enhances (diminishes) mean $\mathrm{Q}_{\text {net }}$ and U10 over the WEP (Fig. 9b-f). Further it shifts the rising branch of the PWC more to the west (east), similar as in the CMIP5 models (see Fig. 12 in Bayr et al. 2018). In agreement with 
(a) Diff mean vertical wind vs. SST bias

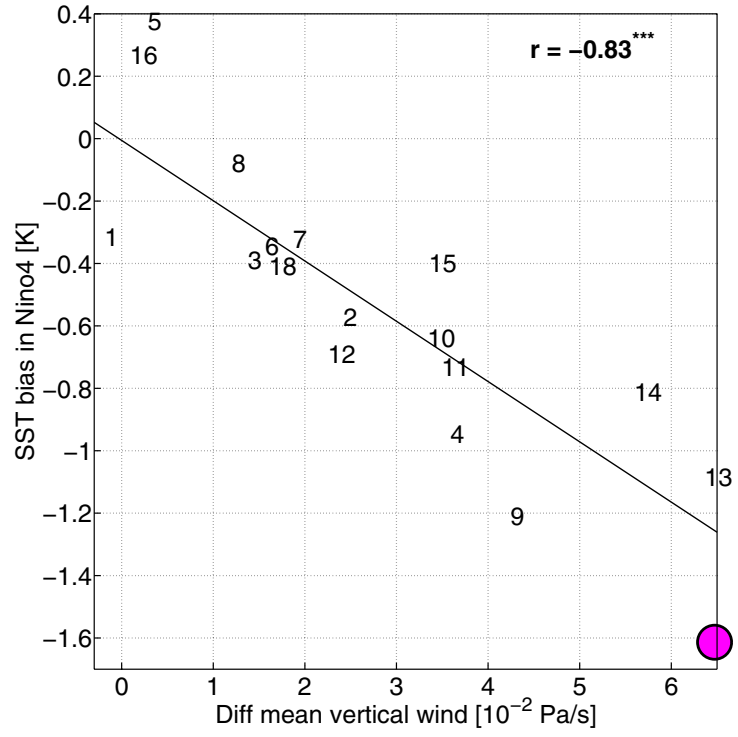

Fig. 7 Difference CMIP5-AMIP5 in a mean vertical wind at $500 \mathrm{hPa}$ in the western Pacific on the X-axis, vs. the relative SST bias in Niño4 (relative to the equatorial Indo-Pacific area mean SST in the (b) Diff mean cloud cover vs. SST bias

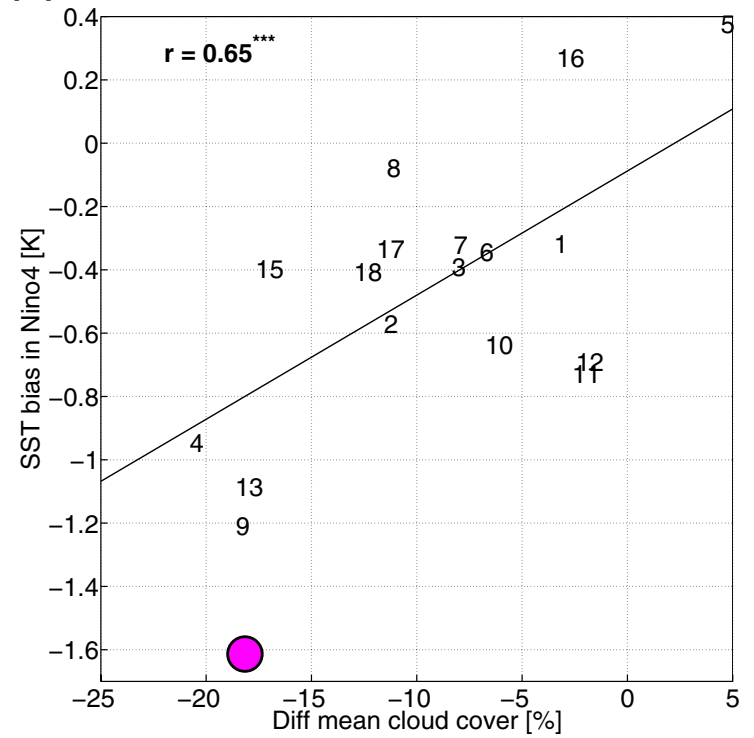

region $\left.40^{\circ} \mathrm{E}-70^{\circ} \mathrm{W}, 15^{\circ} \mathrm{S}-15^{\circ} \mathrm{N}\right)$ on the y-axis; b same as a but here for the difference West $\left(150^{\circ} \mathrm{E}-180^{\circ}, 5^{\circ} \mathrm{S}-5^{\circ} \mathrm{N}\right)$ minus East $\left(120^{\circ} \mathrm{W}-150^{\circ} \mathrm{W}, 5^{\circ} \mathrm{S}-5^{\circ} \mathrm{N}\right)$ in mean cloud cover on the $\mathrm{x}$-axis
Fig. 8 Average cold SST bias of the WEAK sub-ensemble of CMIP5 models, which is implemented in different strengths in the observed SST forcing of sensitivity experiments with the ECHAM5 AMIP-type experiments; The numbers in the header is the average over the Niño4 and Niño3 region, respectively, as marked by the black box

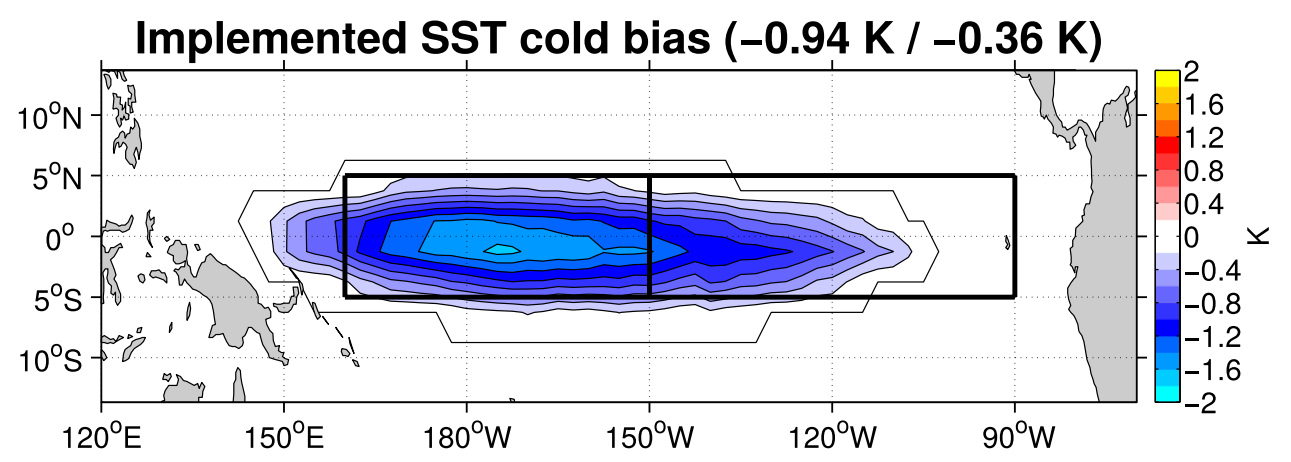

Johnson and Xie (2010) and He et al. (2018) is the relative SST suitable to explain the change in convection and precipitation. The range of the implemented SST biases is similar to the spread in the CMIP5 models, and the spread in the atmospheric mean states, especially of the cold bias experiments, is comparable to those in the CMIP5 and AMIP5 models, as indicated by the gray shaded areas in Fig. 9 .

ECHAM5 exhibits realistic EAF when forced by observed SSTs (control experiment) (Fig. 10). When implementing the cold bias in the SST forcing the error compensation between the two atmospheric feedbacks becomes obvious. Further, the spread in zonal wind and net heat flux feedback (Fig. 10) is similar that that in CMIP5 (Fig. 1a), just by altering the mean state, although all sensitivity experiments contain by definition an identical SST variability. Finally, a warm SST bias enhances the atmospheric feedbacks (Fig. 10).
The atmospheric response to Niño3.4 SST anomalies in the control and sensitivity experiments with ECHAM5 (Fig. 11) is consistent with the AMIP5 (Fig. 2) and CMIP5 sub-ensembles (Figs. 5, 6 in Bayr et al. 2018). The vertical wind response decreases from a warm bias to an increasing cold bias (4th column in Fig. 11). The cloud cover response is quite similar in the $+0.4 \mathrm{~K}$ bias, control and $-0.4 \mathrm{~K}$ bias experiments (Figs. 11e, j, o; 12d), but decreases strongly in the $-0.7 \mathrm{~K}$ bias and $-1.1 \mathrm{~K}$ bias experiments (Figs. 11t, y; 12d). The zonal wind and net heat flux feedback strongly weaken from a warm bias to an increasing cold bias in Niño4 (2nd and 3rd column in Fig. 11) due to the reduced vertical wind and cloud cover response. The positive net heat flux response at the western edge of the Niño4 region in the $-0.7 \mathrm{~K}$ bias and $-1.1 \mathrm{~K}$ bias experiment (Fig. 11r, w) are caused by a positive latent-heat response, when the zonal 
ECHAM5 AMIP-type: Equatorial mean state
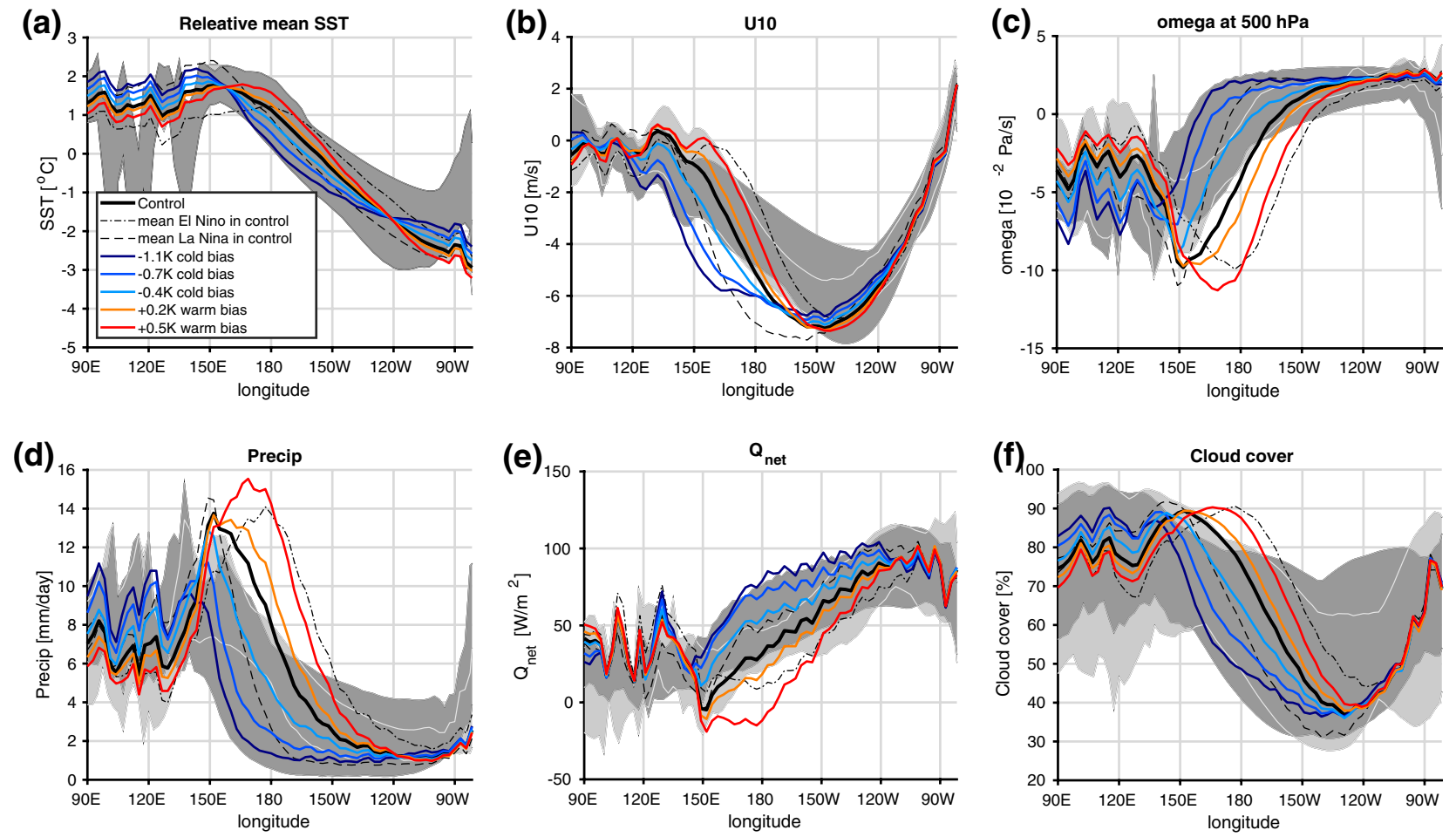

Fig. 9 Same as Fig. 5, but here for ECHAM5 AMIP-type control and sensitivity experiments, in a for SST relative to area mean tropical Indo-Pacific SST, in b for U10, in $\mathbf{c}$ for vertical wind at $500 \mathrm{hPa}$ (negative upward), in $\mathbf{d}$ for precipitation, in $\mathbf{e}$ for Qnet, in $\mathbf{f}$ for total cloud cover. The dark gray shaded area marks the maximal spread in mean states in the CMIP5 models, the light gray shaded area in the AMIP5 models
Fig. 10 Same as Fig. 1b, but here for ECHAM5 AMIP-type control experiment and the individual ECHAM5 AMIPtype sensitivity experiments. The implemented relative SST bias in the Niño4 region is given in the list of experiments on the right

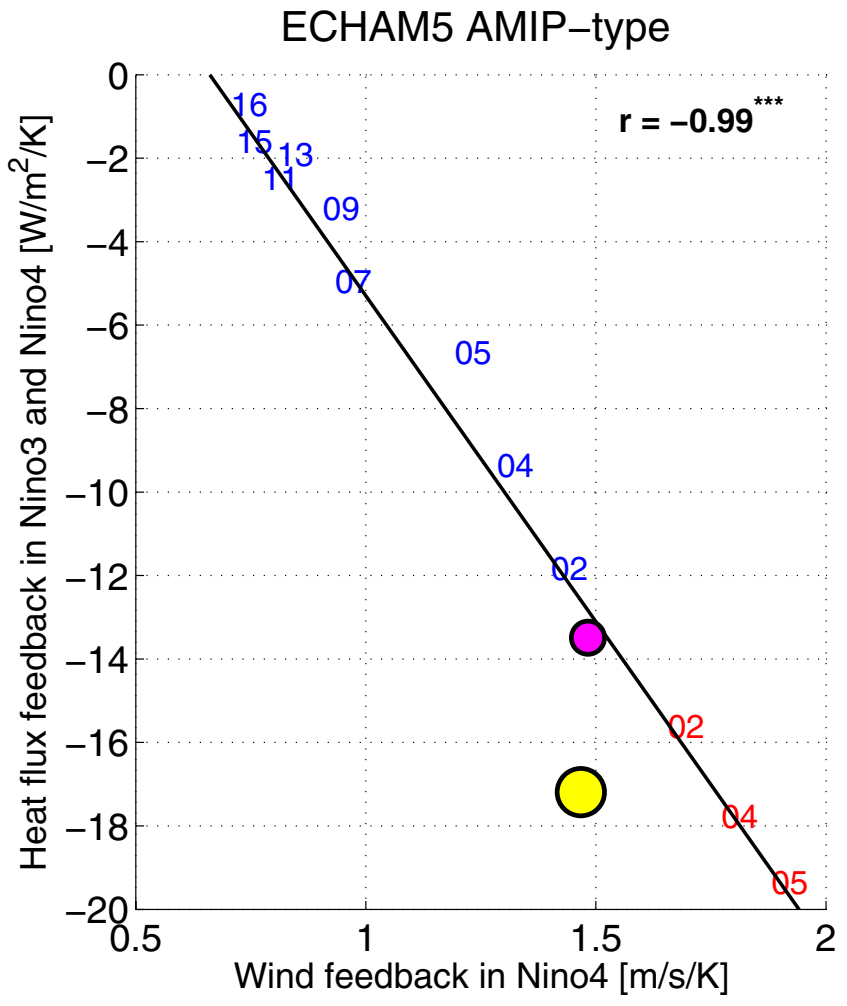

ERA-Interim

ECHAM5 AMIP-type Control

Exp16 [cold bias $=-1.6 \mathrm{~K}$ ]

Exp15 [cold bias $=-1.5 \mathrm{~K}$ ]

Exp13 [cold bias $=-1.3 \mathrm{~K}$ ]

Exp11 [cold bias $=-1.1 \mathrm{~K}$ ]

Exp09 [cold bias $=-0.9 \mathrm{~K}$ ]

Exp07 [cold bias $=-0.7 \mathrm{~K}$ ]

Exp05 [cold bias $=-0.5 \mathrm{~K}$ ]

Exp04 [cold bias $=-0.4 \mathrm{~K}$ ]

Exp02 [cold bias $=-0.2 \mathrm{~K}$ ]

Exp02 [warm bias $=0.2 \mathrm{~K}$ ]

Exp04 [warm bias $=0.4 \mathrm{~K}$ ]

Exp05 [warm bias $=0.5 \mathrm{~K}$ ] 


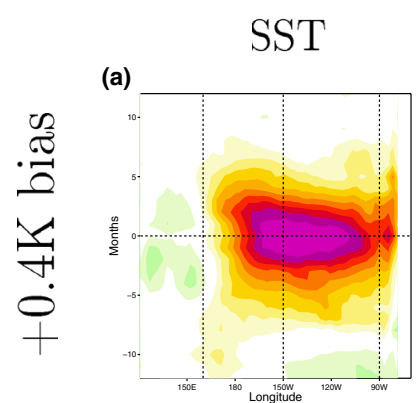

ENSO Composites in ECHAM5 AMIP-type

U10 Qnet $\omega$ at $500 \mathrm{hPa}$

Cloud cover

(b)

(c) (d)

(d)

(e)
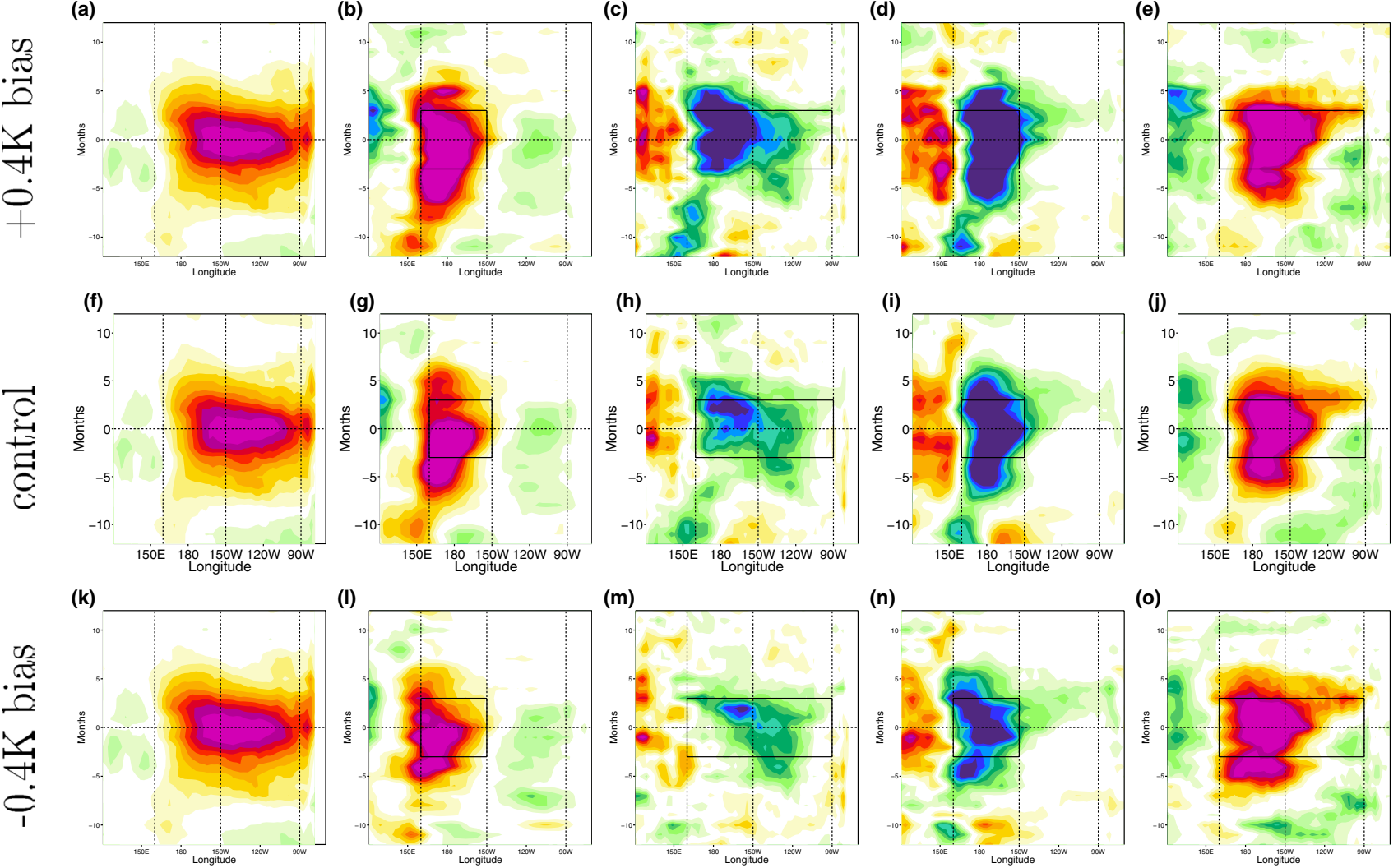

(I)

(m)

(n)
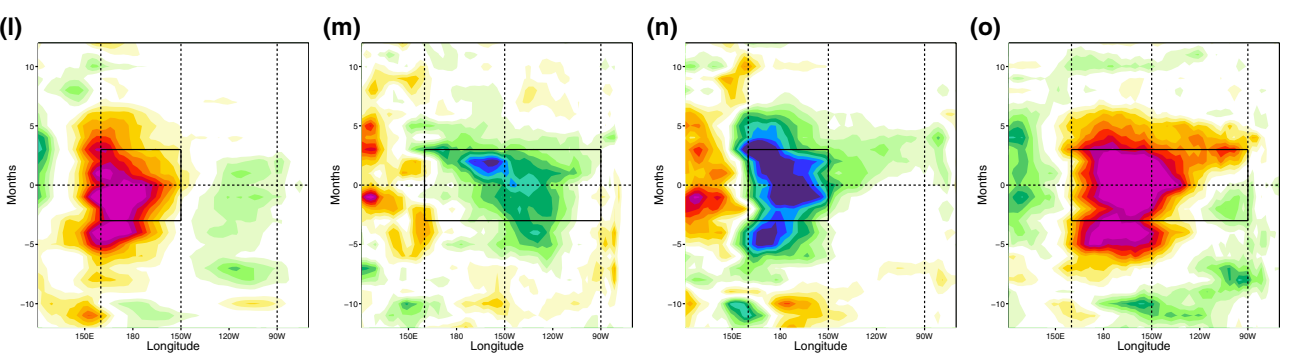

(r)

(s)

(t)
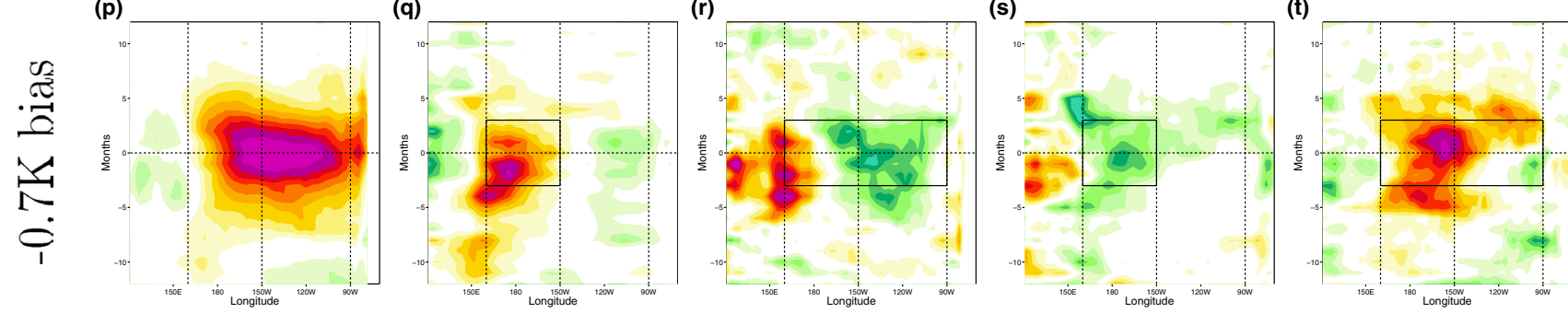

(u)

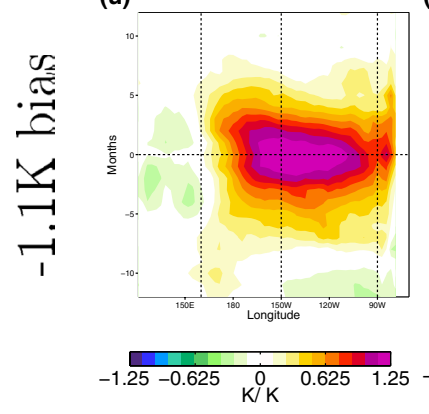

(v)

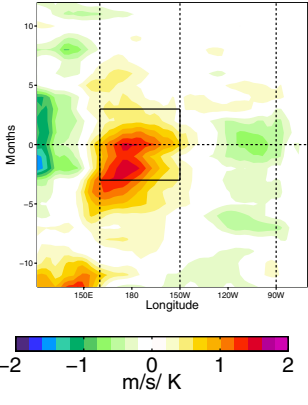

(w)

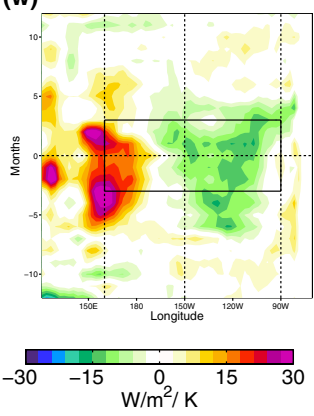

(x)

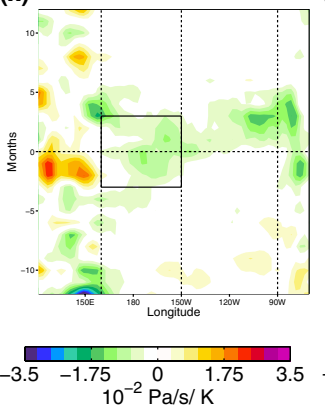

(y)

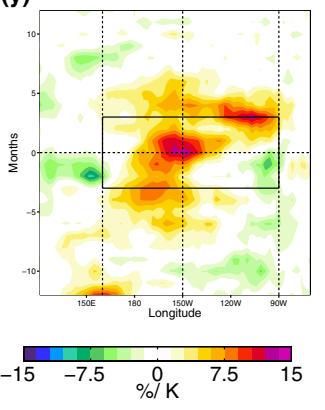

Fig. 11 Same as Fig. 2, but here for ECHAM5 AMIP-type control and sensitivity experiments; $\mathbf{a}-\mathbf{e}$ for $+0.4 \mathrm{~K}$ warm bias, $\mathbf{f}-\mathbf{j}$ same as a-e but here for the ECHAM5 AMIP-type control experiment; k-o same as a-e but here for $-0.4 \mathrm{~K}$ cold bias, $\mathbf{p}-\mathbf{t}$ same as a-e but here for $-0.7 \mathrm{~K}$ cold bias, $\mathbf{u}-\mathbf{y}$ same as $\mathbf{a}-\mathbf{e}$ but here for $-1.1 \mathrm{~K}$ cold bias 


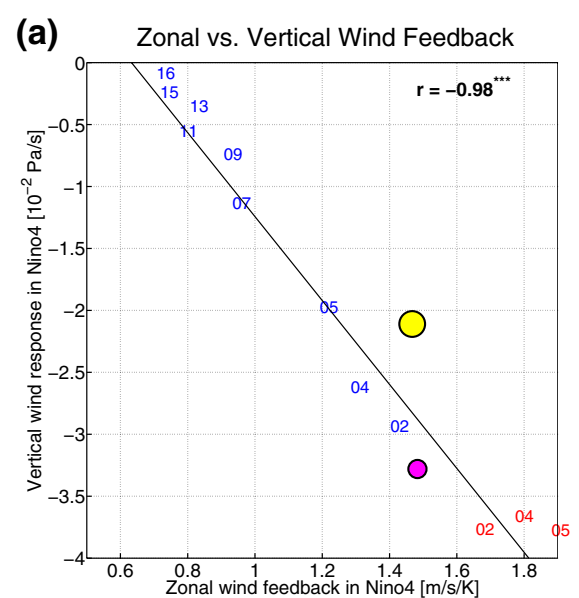

(d)

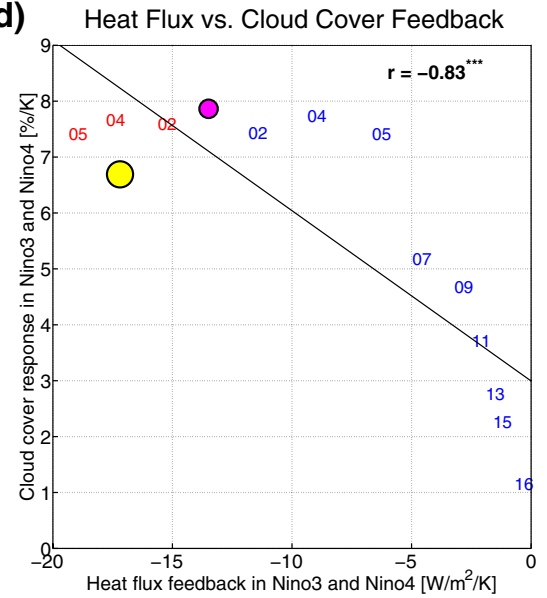

(b) Vertical Wind: Mean vs. Feedback

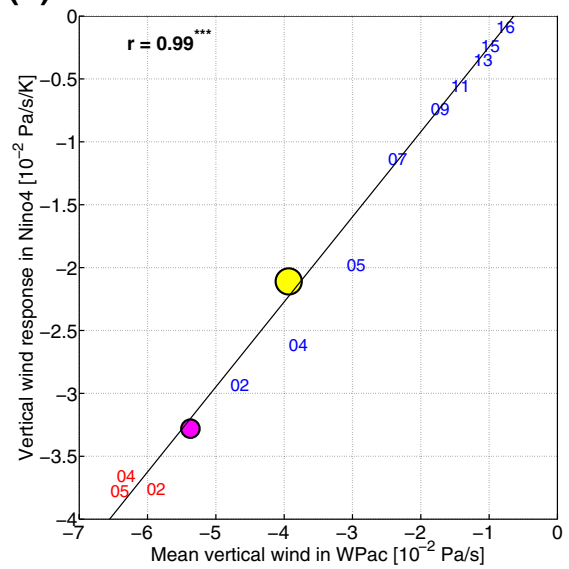

(e) Cloud Cover: Mean vs. Feedback

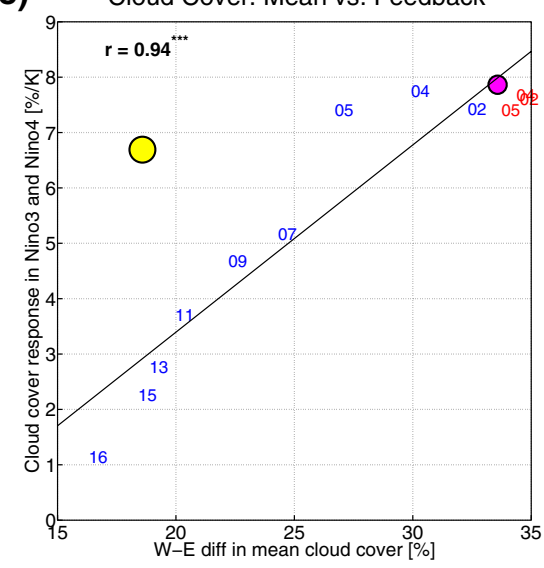

(c) Mean vertical wind vs. SST bias

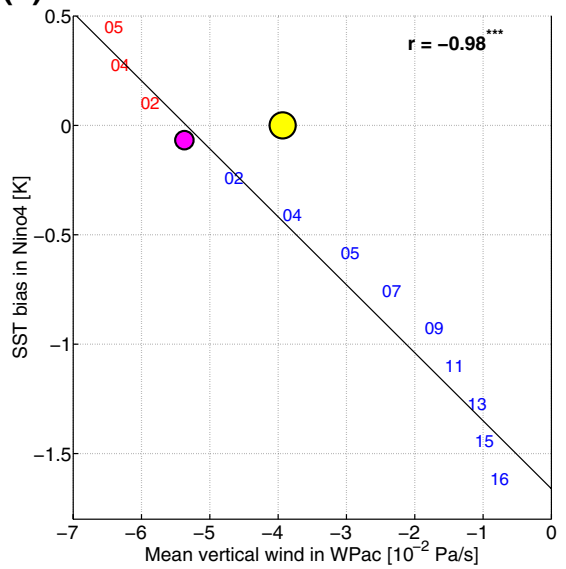

(f)

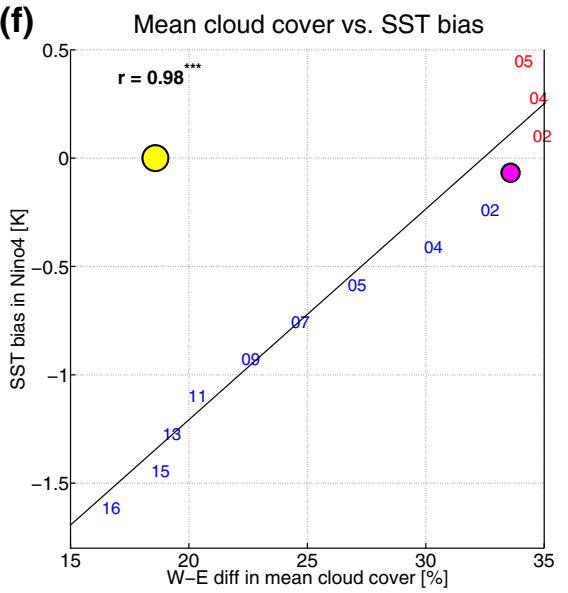

Fig. 12 a, d Same as Fig. 4a, d; b, e same as Fig. 6a, d and c, f same as Fig. 7, but here for ECHAM5 AMIP-type control and sensitivity experiments

wind drops from easterly to zero during El Niño events (not shown).

In the individual sensitivity experiments, the relation between the zonal wind feedback and the vertical wind response (Fig. 12a), the mean vertical wind and the vertical wind response (Fig. 12b) and the SST bias and the mean vertical wind (Fig. 12c) is similar to that in AMIP5 and CMIP5 (Figs. 4, 6, 7), but with stronger correlations. Further, the spread in mean vertical wind, vertical wind response and zonal wind feedback also is similar to that in AMIP5 and CMIP5, so that the spread in the zonal wind feedback could be due to the different mean vertical wind in these models. These analyses also reveal the models need a stronger vertical wind response than that in reanalysis to simulate a similar strength in the zonal wind feedback (see Figs. 4a, b; 12a), while they need a similar mean vertical wind to get the same vertical wind response as that in reanalysis (Figs. 6a, b; 12b).

The situation is more complex regarding the relation between the net heat flux feedback and the cloud cover. There is a non-linear relation between the heat flux feedback and the cloud cover response, in Niño3 and Niño4, as in the $+0.5 \mathrm{~K}$ bias to $-0.5 \mathrm{~K}$ bias experiments the change in the net heat flux feedback is not due to changes in the cloud cover response, which is similar in the experiments (Fig. 12d). The change in the heat flux feedback can be mainly attributed to changes in the latent heat-flux feedback becoming increasingly positive over the western Pacific (not shown). The net heat flux feedback and the cloud cover feedback both strongly decrease in the $-0.7 \mathrm{~K}$ bias to $-1.6 \mathrm{~K}$ bias experiments. The mean cloud cover difference (West Pacific minus East Pacific) is strongly related to the implemented SST bias (Fig. 12f), but is only linear related to the cloud cover response over the combined Niño3/Niño4 region in the $-0.7 \mathrm{~K}$ bias to $-1.6 \mathrm{~K}$ bias experiments (Fig. 12e). Thus, we can only partly explain the differences in the net heat flux feedback by the differences in cloud cover response.

In summary, we can explain by the above sensitivity experiments with identical model physics the strength of zonal wind-SST feedback in AMIP5, CMIP5 and the difference between both by the mean vertical wind in the western Pacific. We can partly explain the strength of the net heat 
flux-SST feedback in the models by mean cloud cover over the combined Niño3 and Niño4 region.

\section{Summary and discussion}

We have investigated the positive zonal wind-SST and negative net heat flux-SST feedback operating in ENSO in AMIP5 and CMIP5 experiments. Both atmospheric feedbacks tend to be stronger in the AMIP5 experiments (on average $77 \%$ of the observed strength) than in the corresponding CMIP5 experiments (on average $46 \%$ of the observed strength), but the feedbacks are still underestimated in nearly all AMIP5 models in comparison to observations. Atmosphere models with a stronger ascent, more precipitation and cloud cover over the western Pacific, indicative of a stronger rising branch of the PWC, tend to have stronger ENSO atmospheric feedbacks (EAF) than models with a weaker rising branch of the PWC. We find a strong relation between the atmospheric mean state and the response of the atmospheric circulation to SST anomalies during ENSO events over the western Pacific in AMIP5 as well as CMIP5, which underlines that the mean state has a substantial influence on the EAF strengths in coupled and uncoupled experiments.

Almost all CMIP5 models have weaker EAF strength than the corresponding AMIP5 models, with a similar ratio in reduction between the zonal wind and net heat flux feedback. This implies some error compensation between the two feedbacks, as previously suggested (Guilyardi et al. 2009b; Kim et al. 2014; Bayr et al. 2018, 2019). The reduction of the EAF strength in CMIP5 in comparison to AMIP5 can be explained to a substantial part by a reduced mean deep convection over the western Pacific, which in turn is caused by an equatorial cold SST bias, in agreement with Bayr et al. (2018).

To underpin these findings we conducted a series of experiments with a single atmosphere model, in which we added in the observed SST forcing an average equatorial SST bias with different strengths and signs, derived from the CMIP5 experiments with the weakest EAF. We show that a cold SST bias weakens the EAF, as it weakens the mean deep convection in the rising branch of PWC, similar to what was observed in the CMIP5 and AMIP5 models. Similarly, a warm SST bias strengthens the EAF due to an increased mean deep convection. The forced AGCM experiments reveal that it is possible to generate a large range of EAF strength with the same model physics but different atmospheric mean states produced by introducing an SST bias.

The studies of Lloyd et al. $(2009,2011,2012)$ described in detail which biases in the model physics hamper a realistic simulation of the atmospheric feedbacks in AGCMs and found that the convection scheme is a major source of uncertainty, as it affects the vertical motion and precipitation as well as the cloud cover and radiation balance. Further, as the AMIP5 experiments employ the same SSTs, the differences in model physics should primarily explain the differences in the EAF strength. We show that models with a stronger mean deep convection in the rising branch of the PWC tend to have stronger EAF. It is not possible to quantify the relative roles of the direct effect of differing model physics on the EAF strength from the indirect effect of the model physics by influencing the mean state. But there is no AGCM that has a strong mean deep convection in the rising branch of the PWC and weak EAF or vice versa. This suggests that the atmospheric mean state, beside the model physics, plays a quite important role for the EAF strength in the AGCMs.

The KCM and MPI-ESM are models that have quite realistic feedbacks in their AGCMs (ECHAM5 and ECHAM6, respectively) but the largest reduction in EAF from AGCM to CGCM, despite different ocean models (NEMO and MPI-OM, respectively). This suggests that the reduction in EAF strength is mostly due to the AGCM. ECHAM5 and ECHAM6 are among the models with the strongest ascent over the western Pacific in the AMIP runs, whereas the KCM and MPI-ESM exhibit the largest cold SST bias in the Niño4 region. It remains an open question why the CGCMs have so different SST biases and therefore different reductions in EAF strength from AMIP5 to CMIP5. A cold equatorial Pacific SST bias is a common problem is current CGCMs and its origin is still under debate (Davey et al. 2002; Guilyardi et al. 2009b; Bayr et al. 2018; Timmermann et al. 2018). Too strong zonal surface winds, too large oceanic upwelling or vertical mixing, and biases in the cloud cover are possible contributors to the equatorial SST bias.

The underestimated EAF hamper a realistic representation of ENSO dynamics (Kim et al. 2014; Bayr et al. 2018, 2019), as there is error compensation between the too weak wind-SST and too weak heat flux-SST feedback in many climate models (Fig. 1a). A too weak forcing by the wind-SST feedback is compensated by a too weak damping by the heat flux feedback (Guilyardi et al. 2009b). In many models the short wave-SST feedback is erroneously positive (Lloyd et al. 2009, 2011, 2012; Bellenger et al. 2014; Bayr et al. 2018), so that in many climate models ENSO is a hybrid of wind-driven and short wave-driven ENSO dynamics (Dommenget 2010; Dommenget et al. 2014). In the most biased models the positive short waveSST feedback accounts for same amount of SST change as the wind-driven ocean dynamics (Bayr et al. 2019). As too weak EAF hamper the simulation of the thermocline, the zonal advection and the Ekman feedback, strong EAF are therefore crucial for a realistic simulation of many ENSO properties, like the asymmetry between El Niño and La Niña (Dommenget et al. 2013; Bayr et al. 2018; 
Timmermann et al. 2018) or the phase locking of ENSO to the annual cycle (Tziperman et al. 1998; Wengel et al. 2018).

In summary we could show that in the AGCMs, beside biases in the model physics, biases in the mean state of the rising branch of the PWC play an important role for the underestimated EAF. Further, the mean deep convection of the rising branch of the PWC is weakening during coupling due to an evolving equatorial cold SST bias and can explain a large part of the reduction of the EAF from AMIP5 to CMIP5. Therefore a realistic atmospheric mean state in both AGCMs and CGCMs seems to be crucial for a realistic simulation of the EAF and ENSO dynamics in the model simulations.

Acknowledgements Open Access funding provided by Projekt DEAL. The authors would like to thank the anonymous reviewers for their constructive comments. We acknowledge the World Climate Research Program's Working Group on Coupled Modeling, the individual modeling groups of the Coupled Model Intercomparison Project (CMIP5) and the Atmospheric Model Intercomparison Project (AMIP5), the ECMWF and NOAA for providing the data sets. The climate model integrations of KCM and ECHAM5 were performed at the Computing Centre of Kiel University and the North-German Supercomputing Alliance (HLRN). This work was supported by the SFB 754 "ClimateBiochemistry Interactions in the tropical Ocean", the European Union's InterDec project, the ARC Centre of Excellence for Climate System Science (Grant CE110001028), the ARC project "Beyond the linear dynamics of the El Niño Southern Oscillation”' (Grant DP120101442). This is a contribution to the Cluster of Excellence "The Future Ocean" at the University of Kiel.

Funding This study was funded by Deutsche Forschungsgemeinschaft (Grant no. SFB754).

Open Access This article is licensed under a Creative Commons Attribution 4.0 International License, which permits use, sharing, adaptation, distribution and reproduction in any medium or format, as long as you give appropriate credit to the original author(s) and the source, provide a link to the Creative Commons licence, and indicate if changes were made. The images or other third party material in this article are included in the article's Creative Commons licence, unless indicated otherwise in a credit line to the material. If material is not included in the article's Creative Commons licence and your intended use is not permitted by statutory regulation or exceeds the permitted use, you will need to obtain permission directly from the copyright holder. To view a copy of this licence, visit http://creativecommons.org/licenses/by/4.0/.

\section{References}

Banzon V, Smith TM, Chin TM, Liu C, Hankins W (2016) A long-term record of blended satellite and in situ sea-surface temperature for climate monitoring, modeling and environmental studies. Earth Syst Sci Data 8:165-176. https://doi.org/10.5194/essd-8-165-2016

Bayr T, Dommenget D (2013) The tropospheric land-sea warming contrast as the driver of tropical sea level pressure changes. J Clim 26:1387-1402. https://doi.org/10.1175/jcli-d-11-00731.1
Bayr T, Dommenget D, Martin T, Power SB (2014) The eastward shift of the Walker circulation in response to global warming and its relationship to ENSO variability. Clim Dyn 43:2747-2763. https ://doi.org/10.1007/s00382-014-2091-y

Bayr T, Latif M, Dommenget D, Wengel C, Harlaß J, Park W (2018) Mean-state dependence of ENSO atmospheric feedbacks in climate models. Clim Dyn 50:3171-3194. https://doi.org/10.1007/ s00382-017-3799-2

Bayr T, Wengel C, Latif M, Dommenget D, Lübbecke J, Park W (2019) Error compensation of ENSO atmospheric feedbacks in climate models and its influence on simulated ENSO dynamics. Clim Dyn 53:155-172. https://doi.org/10.1007/s00382-018-4575-7

Bellenger H, Guilyardi E, Leloup J, Lengaigne M, Vialard J (2014) ENSO representation in climate models: from CMIP3 to CMIP5. Clim Dyn 42:1999-2018. https://doi.org/10.1007/s0038 2-013-1783-z

Davey M et al (2002) STOIC: a study of coupled model climatology and variability in tropical ocean regions. Clim Dyn 18:403-420. https://doi.org/10.1007/s00382-001-0188-6

Dijkstra HA, Neelin JD (1995) Ocean-atmosphere interaction and the tropical climatology. Part II: why the Pacific cold tongue is in the east. J Clim 8:1343-1359. https://doi.org/10.1175/15200442(1995)008\%3c1343:oaiatt\%3e2.0.co;2

Dommenget D (2010) The slab ocean El Niño. Geophys Res Lett 37:L20701. https://doi.org/10.1029/2010g1044888

Dommenget D, Yu Y (2016) The seasonally changing cloud feedbacks contribution to the ENSO seasonal phase-locking. Clim Dyn 1-12. https://doi.org/10.1007/s00382-016-3034-6. http:// link.springer.com/10.1007/s00382-016-3034-6. Accessed 11 Jul 2016

Dommenget D, Bayr T, Frauen C (2013) Analysis of the non-linearity in the pattern and time evolution of El Niño southern oscillation. Clim Dyn 40:2825-2847. https://doi.org/10.1007/ s00382-012-1475-0

Dommenget D, Haase S, Bayr T, Frauen C (2014) Analysis of the Slab Ocean El Nino atmospheric feedbacks in observed and simulated ENSO dynamics. Clim Dyn 42:3187-3205. https:// doi.org/10.1007/s00382-014-2057-0

Gadgil S, Joseph PV, Joshi NV (1984) Ocean-atmosphere coupling over monsoon regions. Nature 312:141-143. https://doi. org/10.1038/312141a0

Graham NE, Barnett TP (1987) Sea surface temperature, surface wind divergence, and convection over tropical oceans. Science 238(80):657-659. https://doi.org/10.1126/science.238.4827.657

Graham FS, Brown JN (2014) El Niño and the southern oscillation. Encycl Nat Res 2014:1-8

Guilyardi E, Braconnot P, Jin F-F, Kim ST, Kolasinski M, Li T, Musat I (2009a) Atmosphere feedbacks during ENSO in a coupled GCM with a modified atmospheric convection scheme. J Clim 22:5698-5718. https://doi.org/10.1175/2009jcli2815.1

Guilyardi E, Wittenberg A, Fedorov A, Collins M, Wang C, Capotondi A, van Oldenborgh GJ, Stockdale T (2009b) Understanding El Niño in ocean-atmosphere general circulation models: progress and challenges. Bull Am Meteorol Soc 90:325-340. https://doi.org/10.1175/2008bams2387.1

He J, Johnson NC, Vecchi GA, Kirtman B, Wittenberg AT, Sturm S (2018) Precipitation sensitivity to local variations in tropical sea surface temperature. J Clim 31:9225-9238. https://doi. org/10.1175/jcli-d-18-0262.1

Jin F-F (1997) An equatorial ocean recharge paradigm for ENSO. Part I: conceptual model. J Atmos Sci 54:811-829. https://doi. org/10.1175/1520-0469(1997)054\%3c0830:aeorpf\%3e2.0.co;2

Johnson NC, Xie SP (2010) Changes in the sea surface temperature threshold for tropical convection. Nat Geosci 3:842-845. https ://doi.org/10.1038/ngeo 1008 
Kim ST, Cai W, Jin FF, Yu JY (2014) ENSO stability in coupled climate models and its association with mean state. Clim Dyn 42:3313-3321. https://doi.org/10.1007/s00382-013-1833-6

Lloyd J, Guilyardi E, Weller H, Slingo J (2009) The role of atmosphere feedbacks during ENSO in the CMIP3 models. Atmos Sci Lett 10:170-176. https://doi.org/10.1002/asl.227

Lloyd J, Guilyardi E, Weller H (2011) The role of atmosphere feedbacks during ENSO in the CMIP3 models. Part II: using AMIP runs to understand the heat flux feedback mechanisms. Clim Dyn 37:1271-1292. https://doi.org/10.1175/jcli-d-11-00178.1

Lloyd J, Guilyardi E, Weller H (2012) The role of atmosphere feedbacks during ENSO in the CMIP3 models. Part III: the shortwave flux feedback. J Clim 25:4275-4293. https://doi. org/10.1175/jcli-d-11-00178.1

Madec G (2008) NEMO ocean engine. In: Note du Pole modélisation 27, Inst. Pierre-Simon Laplace, p 193

Madec G, Delecluse P, Imbard M, Lévy C (1998) OPA 8.1 Ocean general circulation model manual. In: Note du Pole modélisation 11, Inst. Pierre-Simon Laplace, p 91

Neelin JD, Battisti DS, Hirst AC, Jin F-F, Wakata Y, Yamagata T, Zebiak SE (1998) ENSO theory. J Geophys Res 103:14261. https ://doi.org/10.1029/97jc03424

Park W, Keenlyside NS, Latif M, Ströh A, Redler R, Roeckner E, Madec G (2009) Tropical pacific climate and its response to global warming in the Kiel climate model. J Clim 22:71-92. https ://doi.org/10.1175/2008jcli2261.1

Philander S (1990) El Niño, La Niña, and the southern oscillation. Academic Press, San Diego, p 293

Roeckner E et al (2003) The atmospheric general circulation model ECHAM5. Part I: model description, report 349. Max Planck Institute for Meteorology, Hamburg, Germany, p 140

Rossow WB, Schiffer RA (1999) Advances in understandig clouds from ISCCP. Bull Am Meteor Soc 80:2261-2287. https://doi. org/10.1175/1520-0477(1999)080\%3c2261:aiucfi\%3e2.0.co;2

Simmons A, Uppala S, Dee D, Kobayashi S (2007) ERA-Interim: new ECMWF reanalysis products from 1989 onwards. ECMWF Newsl 110:25-35

Taylor KE, Stouffer RJ, Meehl GA (2012) An overview of CMIP5 and the experiment design. Bull Am Meteorol Soc 93:485-498. https ://doi.org/10.1175/bams-d-11-00094.1
Timmermann A et al (2018) El Niño-southern oscillation complexity. Nature 559:535-545. https://doi.org/10.1038/s41586-018-0252-6

Tompkins AM (2001) On the relationship between tropical convection and sea surface temperature. J Clim 14:633-637

Trenberth KE (1997) The definition of El Niño. Bull Am Meteorol Soc 78:2771-2778

Tziperman E, Cane MA, Zebiak SE, Xue Y, Blumenthal B (1998) Locking of El Nino's peak time to the end of the calendar year in the delayed oscillator picture of ENSO. J Clim 11:2191-2199. https://doi.org/10.1175/1520-0442(1998)011\%3c2191:loeno s\%3e2.0.co;2

Vijayeta A, Dommenget D (2018) An evaluation of ENSO dynamics in CMIP simulations in the framework of the recharge oscillator model. Clim Dyn 1:1-19. https://doi.org/10.1007/s0038 2-017-3981-6

Wang C, Picaut J (2004) Understanding ENSO physics-a review. Earth's Clim Am Geophys Union 2004:21-48

Wengel C, Latif M, Park W, Harlaß J, Bayr T (2018) Seasonal ENSO phase locking in the Kiel Climate Model: the importance of the equatorial cold sea surface temperature bias. Clim Dyn 50:901919. https://doi.org/10.1007/s00382-017-3648-3

Xie P, Arkin PA (1997) Global precipitation: a 17-year monthly analysis based on gauge observations, satellite estimates, and numerical model outputs. Bull Am Meteorol Soc 78:2539-2558. https://doi. org/10.1175/1520-0477(1997)078\%3c2539:gpayma\%3e2.0.co;2

Yu B, Zwiers FW (2010) Changes in equatorial atmospheric zonal circulations in recent decades. Geophys Res Lett 37:L05701

Yu B, Zwiers FW, Boer GJ, Ting MF (2012) Structure and variances of equatorial zonal circulation in a multimodel ensemble. Clim Dyn. https://doi.org/10.1007/s00382-012-1372-6

Publisher's Note Springer Nature remains neutral with regard to jurisdictional claims in published maps and institutional affiliations. 